1 Fouling and inactivation of titanium dioxide-based photocatalytic systems

2

3

4 5

6

7

8

9

10

11

12

13

14

Keywords: Titanium dioxide; Fouling; Inactivation; photocatlysis; aquatic system
NSW 2007, Australia

${ }^{\mathrm{b}}$ CRC CARE, PO Box 486, Salisbury, SA 5106, Australia

${ }^{\text {c }}$ Faculty of Science, University of Technology Sydney, NSW 2007, Australia

*Corresponding author email: hokyong.shon-1@uts.edu.au, Phone: +61 29514 2629, fax: +61295142633 
1 Titanium dioxide $\left(\mathrm{TiO}_{2}\right)$ is an important photocatalyst for the treatment of water and

2 wastewater. It is used in a range of methods to remove pollutants from water. The ability of

$3 \mathrm{TiO}_{2}$ to act as a photocatalyst was shown by Fujishima and Honda [1] Formenti, et al. [2],

4 and Djeghri, et al. [3] in the early 1970s. Initial work focused on the electrolysis of water to

5 produce hydrogen $\left(\mathrm{H}_{2-}\right)$ as well as the breakdown of simple alkanes. Since then, $\mathrm{TiO}_{2}$ has

6 been shown to be capable of breaking down a wide variety of compounds including various

7 pesticides [4], bisphenol-A [5], pharmaceuticals [6], solvents such as trichloroethylene [7]

8 and many others. This ability to breakdown a wide range of targets has made it an attractive

9 material for the remediation of contaminated water. However, one major issue for all

10 catalysts is that of fouling and poisoning of the material and $\mathrm{TiO}_{2}$ is no exception.

11 Deactivation can occur in a number of different ways, and different foulants will have

12 different effects on a given target degradation..

13 the heart of any $\mathrm{TiO}_{2}$-based photocatalytic system is the generation of electron-hole pairs

14 from incident radiation. The band gap for a given $\mathrm{TiO}_{2}$ catalyst depends on the production method, doping and crystal phases. For pure anatase $\mathrm{TiO}_{2}$, the gap is $\sim 3.2 \mathrm{eV}$ and for pure rutile $\mathrm{TiO}_{2}$, it is $\sim 3.0 \mathrm{eV}$ [8]. These energies correspond to an excitation wavelength in the near UV region of the spectrum $(\lambda<411 \mathrm{~nm}$ for rutile and $\lambda<385 \mathrm{~nm}$ for anatase) [9]. In an

18 isolated system, photogenerated charges will normally quickly relax into trapped states before undergoing recombination after a few microseconds [10] accompanied by the release of heat. In a solution, charge carriers can transfer to species adsorbed on the surface of $\mathrm{TiO}_{2}$, causing

21 oxidation or reductionleading to the direct breakdown of target compounds. This charge 22 transfer can also produce highly reactive radicals from adsorbed species such as $\mathrm{H}_{2} \mathrm{O}, \mathrm{OH}^{-}$or $23 \mathrm{O}_{2}$ as shown in the following reactions:

$$
\mathrm{Ti}+\mathrm{OH}_{a d s}+h^{+} \leftrightarrow \mathrm{Ti}-\mathrm{OH}
$$




$$
\begin{gathered}
\mathrm{Ti}+\mathrm{OH}_{2 a d s}+h^{+} \leftrightarrow \mathrm{Ti}-\mathrm{OH} \cdot+\mathrm{H}^{+} \\
\mathrm{O}_{2 a d s}+e^{-} \leftrightarrow \mathrm{O}_{2}^{-} . \\
\mathrm{O}_{2}^{-\cdot}+e^{-}+H^{+} \leftrightarrow \mathrm{H}_{2} \mathrm{O}_{2} \\
\mathrm{O}_{2}^{-\cdot}+\mathrm{H}^{+} \leftrightarrow \mathrm{H}_{2} \mathrm{O} .
\end{gathered}
$$

1 The radical species can then react with target compounds causing their breakdown. The fact

2 that there are two primary pathways for the breakdown in targets (direct hole/electron attack

3 or indirect radical attack) leads to different fouling mechanisms as well as differing effects

4 for the same foulant on different targets.

5 The position of the bands shifts with $\mathrm{pH}$ (though the band gap remains constant) [11].

6 Therefore, only certain species may be oxidized/reduced by $\mathrm{TiO}_{2}$ within a certain $\mathrm{pH}$ range

7 [12]. The value of the quasi-fermi level has been estimated as:

$$
E_{f}(p H)=E_{F}(0)-0.059 p H
$$

8 with $E_{F}(0)=-0.05 V^{1}[12,13]$ for anatase and 0.15 for rutile [11]. At $\mathrm{pH} 7$, for example,

$9 \quad E_{\mathrm{f}}$ for anatase is approximately $-0.46 \mathrm{~V}$.

10 In this review, we examine the factors that inhibit photocatalyst performance and we examine

11 the mechanisms that underpin these factors. This area is of immense importance as a 12 thorough understanding of the pathways that lead to the inhibition of $\mathrm{TiO}_{2}$ photocatalyst 13 systems are vital in order to create useful photocatalytic systems. In this work, the literature is 14 reviewed to determine the effect of common inorganic ions and organic compounds on $\mathrm{TiO}_{2}$. 15 The effect of supports and the stability of immobilised films are also explored. Finally 16 methods for regeneration and prevention are examined.

1 All potentials listed in this paper are with reference to the Standard Hydrogen Electrode(SHE) 


\section{INHIBITORY MECHANISMS}

2 There are a number of mechanisms by which a given species can inhibit the breakdown of

3 target compounds with $\mathrm{TiO}_{2}$. These are listed with example foulants in Table 1 .

4 The first mechanism is surface blockage. Some compounds can interfere with the breakdown

5 of targets by occupying sites on the surface of $\mathrm{TiO}_{2}$. The blocked sites allow neither target

6 compounds nor $\mathrm{O}_{2} / \mathrm{H}_{2} \mathrm{O} / \mathrm{OH}^{-}$to adsorb to the surface and react with photogenerated charges.

7 This is a common effect to many species as it requires only that an interfering compound

8 adsorb strongly to the surface. A related mechanism is aggregation of catalyst particles in

9 suspension resulted in a reduced surface area available for reactions. Certain species such as

10 divalent ions can promote this phenomenon by acting as a bridge or adhesive between the

11 particles. [14, 15]. Immobilized film reactors are not susceptible to inactivation due to

12 aggregation as the particles are not in suspension[16].

13 Interfering compounds may scavenge the photogenerate active species such as holes, $\mathrm{OH}^{*}$-,

14 or $\mathrm{O} 2 *_{-}$, either removing them or transforming them into less active ones [17]. This can have

15 a significant effect on the overall rate. However, hole/electron scavengers can have an

16 enhancing effect in some cases. For example, if a reaction pathway utilizes holes for the

17 desired chemical transformation then an electron scavenger will decrease the recombination

18 rate of charges by acting as an electron trap. The trapping of charges however can also be a

19 fouling mechanism. The adsorption of some foulants to surfaces can introduce new energy

20 states within the bandgap of $\mathrm{TiO}_{2}$. These states may act as recombination centres thereby

21 decreasing the number of free carriers available for reactions and reducing the degradation

22 rate.

23 Some compounds can absorb light in the active region of $\mathrm{TiO}_{2}(\lambda<411 \mathrm{~nm}$ for rutile and $\lambda<$

$24385 \mathrm{~nm}$ for anatase) [9]. If present in the water matrix in sufficient amounts such a compound 
1 will reduce the effective illumination of the catalyst, decreasing the charge generation and

2 hence the overall reaction rate. A relatively rare inhibitory mechanism involves compounds

3 that widen the bandgap of $\mathrm{TiO}_{2}$ [18]. This will reduce the number of useful photons absorbed

4 by the catalyst and thus reduce the charge generation rate and subsequently the overall

5 reaction rate.

6 The dominant mechanism for a particular combination of target and foulant depends on many

7 parameters. A foulant that primarily blocks adsorption may have little effect on targets that

8 are degraded primarily though indirect radical action. Conversely, a strong radical scavenger

9 may have little effect on a target degraded by direct hole reactions[19]. For example, radical scavenging is a large source of inhibition for compounds such as phenol, which do not adsorb

11 significantly at the $\mathrm{TiO}_{2}$ surface as reported by Naeem and Feng [20].

\section{THE EFFECTS OF SALTS AND IONS}

Inorganic ions are commonly found in all natural water systems and they originate from a variety of geological and biological sources. Unlike many organic molecules, they are not subject to breakdown by photocatalysis.

\subsection{Ionic strength}

High ionic strength can act as either a promoter, foulant, or neither, depending on the target compound(s). The aqueous ionic strength can alter the adsorption properties of targets to the surface of $\mathrm{TiO}_{2}$. Dionysiou, et al. [21] examined the effect of ionic strength on the breakdown of 4-chlorobenzoic acid and reported a slight decrease in degradation rate with increasing $\mathrm{KNO}_{3}$ concentrations up to $500 \mathrm{mM}$, with the primary effect being a reduction in the amount of adsorption. Aguedach et al. [22] reported a large increase in the breakdown of the dye Reactive Black 5 (RB5) at concentrations as low as $10 \mathrm{mM}$ with increasing salt concentration. This was attributed to increased adsorption of RB5 due to compression of the 
1 electric double layer and neutralization of positive surface charges. They also found that

2 different ions affect the rate of breakdown with $\mathrm{Ca}^{2+}>\mathrm{K}^{+}>\mathrm{Na}^{+} \approx \mathrm{Li}^{+}$.

3 Anions also affect the reaction rates with hydroxide radicals (Table 2). For example, high 4 levels $(>500 \mathrm{mM})$ of chloride ions are reported to greatly increase the rate of breakdown of 5 naphthalene; $2.4 \mathrm{~mol} / \mathrm{L}$ of chloride gave a rate of more than 4 times that measured in the 6 absence of chloride [23]. It was initially suggested that this was due to an increase in the

7 volatility of naphthalene at higher ionic strength but later experiments showed this not to be

8 the case. Instead, they attributed the increase to the "salting out" of neutral organics in strong 9 salt solutions, leading to an increase in adsorption onto the $\mathrm{TiO}_{2}$ surface. While high levels of $10 \mathrm{Cl}^{-}$were shown to increase the breakdown of naphthalene, they inhibited the removal of 11 hydrophilic breakdown products such as 1,4-naphthoquinone, supporting the salting out 12 theory. A similar phenomenon was reported by Yang, et al. [24] who studied benzene, 13 naphthalene, and Orange II. In contrast to these reports, no effect due to ionic strength was 14 observed for the breakdown of chloroform [25], phenol, cyclohexane, or resorcinol [26]. It is 15 clear that there is no general trend for the effect of ionic strength on the degradation rate and 16 the effect on a given target will be difficult to predict.

\section{$17 \quad 3.2$ Anions}

$18 \quad 3.2 .1 \quad$ Chloride and other halogens

19 Chloride is a commonly found anion in the environment as well as in the laboratory where it 20 is used as a counter ion. Other halogens, particularly iodine and bromine are also common in 21 both natural and artificial waters. Halogens can cause inhibition primarily by surface 22 blockage or scavenging of radicals. Halogens, including chlorine can undergo a variety of 23 reactions that affect the photocatalysis attributed to hydroxyl species [26, 27]: 


$$
\begin{gathered}
\mathrm{Cl}^{-}+\mathrm{OH} \cdot \leftrightarrow \mathrm{ClOH}^{\cdot^{-}} \\
\mathrm{ClOH}^{{ }^{-}} \rightarrow \mathrm{Cl} \cdot \mathrm{HO}^{-} \\
\mathrm{ClOH} \cdot^{-}+\mathrm{H}^{+} \rightarrow \mathrm{Cl} \cdot+\mathrm{H}_{2} \mathrm{O} \\
\mathrm{Cl} \cdot+\mathrm{Cl}^{-} \rightarrow \mathrm{Cl}_{2}^{-} \\
\mathrm{Cl}_{2}^{-} \rightarrow \mathrm{Cl} \cdot+\mathrm{Cl}^{-}
\end{gathered}
$$

1 The reactions (7-11) also proceed with other halogens. Hydroxyl radicals can reversibly react

2 with chloride ions to produce a chlorohydroxide radical species (Eq (7)). These can in turn

3 form chloride radicals and hydroxide ions, Eq (8), or react with a proton to produce a chloride

4 radical and water, Eq (9). The reverse reaction of Eq (7) is rapid (on the order of $10^{7}-10^{9} \mathrm{~s}^{-1}$

5 [26]) so this will dominate over Eq (9) unless there is sufficient $\mathrm{H}^{+}$present. Thus, the

6 inhibition of photocatalysis by halogens is $\mathrm{pH}$ dependent process with the inhibition

7 increasing with the decrease in $\mathrm{pH}$. In the case of chlorine, shifting from $\mathrm{pH} 1$ to 9 causes a

8 drop in the scavenging rate of 4 orders of magnitude [28]. Although both bromine [26] and

9 iodine are stronger scavengers than chlorine, chlorine is more common and thus more of a

10 concern with regard to inhibition of photocatalysis. Other halogens can act as strong hole

11 scavengers. Iodine in particular [29] has been shown to be a powerful hole scavenger and it is

12 commonly used to supress direct hole reactions in order to determine the primary reaction

13 mechanism for a given target [30, 31]. Chen, et al. [30] found that the presence of $10 \mathrm{mM}^{-} \mathrm{I}^{-}$

14 slowed the breakdown of Acid Orange 7 by approximately $75 \%$, due to the scavenging of

15 holes. Further examples can be seen in Table 3.

\subsubsection{Phosphate}

17 Phosphate is a highly problematic ion in the context of photocatalytic inhibition, though with a strong dependence on $\mathrm{pH}$. Examples of the effects of phosphate can be seen in Table 4. At high $\mathrm{pH}, \mathrm{HPO}_{4}{ }^{2-}$ dominates in solution, at $\mathrm{pH}$ near $7, \mathrm{H}_{2} \mathrm{PO}_{4}^{-}$, and at low $\mathrm{pH}, \mathrm{H}_{3} \mathrm{PO}_{4}$. Phosphate primarily acts as a inhibitor by surface blockage, which is attributed to the ability 
1 of $\mathrm{H}_{2} \mathrm{PO}_{4}{ }^{-}$to form a very stable bidentate complex on the surface of $\mathrm{TiO}_{2}$ [32]. The removal

2 of this surface typically requires rinsing with a basic solution such as $0.1 \mathrm{M} \mathrm{NaOH}$ or

$3 \mathrm{NaHCO}_{3}$ [17]. Other forms of phosphate also adsorb to the $\mathrm{TiO}_{2}$ surface although they do so

4 much less strongly than $\mathrm{H}_{2} \mathrm{PO}_{4}{ }^{-}$, resulting in a $\mathrm{pH}$ dependence on the inhibition mechanism.

5 Phosphate can also act as a promoter for certain targets [33]. Phosphate on the surface of

$6 \mathrm{TiO}_{2}$ has a negative charge, drawing photogenerated holes to the surface. These holes can

7 react directly with adsorbed substrates or surface hydroxyl groups of phosphate but may also

8 block the adsorption of many species and thus may have an overall negative effect on the

9 reaction rate. However, phosphate can form strong hydrogen bonds with $\mathrm{H}_{2} \mathrm{O}$, anchoring it

10 near the surface allowing for efficient charge transfer to create free $\mathrm{OH}$ radicals[34] and

$11 \mathrm{H}_{2} \mathrm{O}_{2}$ [35]. These can react with substances near, but not adsorbed, to the surface increasing

12 their breakdown rate [33-35].

$13 \quad 3.2 .3 \quad$ Sulfate

14 Sulfate ions adsorb strongly to the surface of $\mathrm{TiO}_{2}$ and act as scavengers of $\mathrm{OH}$ radicals

15 causing inhibition. Like phosphate the presence of adsorbed sulphate can increase the amount

16 of $\mathrm{H}_{2} \mathrm{O}_{2}$ produced for certain targets though the opposite effect is seen for some targets[35].

17 The mechanism behind this has not been fully explained. Sulphate radicals exhibit a high

18 activity toward many targets, unlike other scavenging-produced radicals [36] and are used in

19 UV/persulfate oxidation systems. This high activity can result in a large increase in the

20 breakdown of susceptible targets [37-39]. Examples of inhibition and promotion due to

21 sulphate are shown in Table 5. 
1 Carbonate is another ion that is extremely common in natural and artificial waters. Aside

2 from artificial sources, natural sources include many mineral and rock formations such as

3 limestone, which are composed mainly of $\mathrm{CaCO}_{3}$.

4 Of particular concern is that the $\mathrm{CO}_{3}{ }^{2-}$ ion is an efficient scavenger, 46 times faster than

$5 \mathrm{HCO}_{3}{ }^{-}$. Carbonate radicals have also been shown to exhibit significant reactivity towards

6 certain compounds, particularly nitrogen-containing organics [40,41]. This is a likely

7 explanation for the enhanced degradation seen in the presence of some targets such as aniline

8 [42] and dimethoate [43]. Carbonate can also combine with other ions such as calcium to

9 produce precipitates that can reduce the effective illumination in a reactor by absorption and

10 scattering [44]. Table 6 presents data on the effect of carbonate on the breakdown of selected

11 target compounds.

$12 \quad 3.2 .5 \quad$ Nitrate

13 Some researchers have reported a slight depressing effect from nitrate on photocatalytic 14 activity due to a combination of radical scavenging as well as filtering of UV light [45, 46] 15 although others have reported no significant effects [47, 48]. The scavenging ability of 16 nitrate, however, is much less than other common ions and so typically contributes little to 17 the inhibition of processes. Examples of the effect of nitrate can be seen in Table 7. Nitrate can also act as a promoter in theory. It can undergo a photolytic reaction to produce nitrite and an oxygen radical when illuminated in the mid UV light range (absorption maximum at $302 \mathrm{~nm})$ [49]:

$$
\mathrm{NO}_{3}^{-}+h v \rightarrow \mathrm{NO}_{2}+\mathrm{O}^{-}
$$

21 However, most of the reported systems do not expose the reactor to significant amounts of 22 light of the necessary wavelength for this reaction to occur (320 nm is a common cut-off wavelength for illumination). Some studies, however, reported an increase in the breakdown 
1 of targets that was attributed to this effect $[43,50]$ despite the low levels of mid UV light

2 producedfrom their systems.

3 It is clear that many common anions can have large effects on the breakdown of contaminants

4 primarily by surface blockage and radical scavenging. Of particular concern are carbonates,

5 chlorine, and sulphates, which are present in many groundwater systems in relatively high

6 levels. However as is always the case, whether a given foulant is an issue will depend on the

7 degradation mechanism of a given compound.

\section{$8 \quad 3.3$ Cations}

9 An important issue when analysing data concerning the effect of cations is that many studies

10 report the use of chloride as the corresponding anion [17] due to the typically high solubility

11 it imparts in water. However, the introduction of chloride ions into solution can itself have an

12 inhibitory effect and so some of the reported rate reductions may be due to the effects of

13 chloride rather than solely attributed to a particular cation.

14 Some metal ions can undergo redox processes with photogenerated electrons/holes:

$$
\begin{aligned}
& M^{x+}+e^{-} \leftrightarrow M^{x-1+} \\
& M^{x-1+}+h^{+} \leftrightarrow M^{x+}
\end{aligned}
$$

15 where $\mathrm{M}$ is a metal. Such metals therefore act as inhibitors by scavenging free charges in

16 "short circuit" reactions. The redox potential for the reaction must be more negative than the

17 valence band and more positive than the conduction band of $\mathrm{TiO}_{2}$ in order for the metal to be 18 oxidized or reduced, respectively. This is the case for $\mathrm{Mn}^{2+} / \mathrm{Mn}^{3+}, \mathrm{Cu}^{2+}, \mathrm{Fe}^{3+}, \mathrm{Co}^{2+}$ and others as shown in Table 8. This often leads to an initial increase in the degradation rates due to

20 scavenging of electrons which lasts until the metal has been consumed, and so many metals

21 have been reported to act as promoters rather than inhibitors [9, 51]. Metal cations may also

22 lead to a reduction in breakdown rates due to the build-up of species on the surface of the 
1 catalyst. Some metals $(\mathrm{Fe}, \mathrm{Cu})$ can undergo Fenton-type reactions with $\mathrm{H}_{2} \mathrm{O}_{2}$ and protons to

2 produce hydroxide radicals [9]:

$$
\mathrm{M}^{n+}+\mathrm{H}_{2} \mathrm{O}_{2}+\mathrm{H}^{+} \rightarrow \mathrm{M}^{(n+1)}+\mathrm{HO} \cdot+\mathrm{HO}^{-}
$$

3 The reduced metal ions can then be regenerated by reduction with photogenerated electrons

4 as in reaction (13). Furthermore, metals may foul the $\mathrm{TiO}_{2}$ surface by forming precipitates

5 such as oxides or hydroxides.

$6 \quad$ 3.3.1 Sodium, calcium, potassium

7 Sodium, calcium and potassium are all common in natural waters and have been shown to

8 have almost no effect on the breakdown rate of various targets [52], particularly when the $\mathrm{pH}$

9 is less than the point of zero charge (PZC). At lower $\mathrm{pH}$, the surface of $\mathrm{TiO}_{2}$ is positively

10 charged, repelling cations and preventing them from even causing simple site blockage. At

$11 \mathrm{pH}>\mathrm{PZC}$ of $\mathrm{Na}^{+}, \mathrm{Ca}^{2+}$, and $\mathrm{K}^{+}$can have a slight inhibitory effect due to their weak adsorption

12 to the surface. $\mathrm{Ca}^{2+}$ and some other divalent ions can also cause aggregation when a particle

13 slurry is used, which will reduce the effective surface area of the catalyst $[14,15,53]$. They

14 have also shown to complex with certain targets to prevent their efficient degradation,

15 including phenol [20]. Divalent ions such as $\mathrm{Ca}^{2+}$ and $\mathrm{Mg}^{2+}$ have been reported to enhance

16 the breakdown of some anionic compounds at $\mathrm{pH}>\mathrm{PZC}$, presumably due to reducing the

17 electrostatic repulsion [54] or bridging structures [53].

$18 \quad 3.3 .2 \quad$ Manganese

19 Manganese has been shown to significantly inhibit photocatalysis on $\mathrm{TiO}_{2}$ at very low levels.

20 Burns, et al. [17] reported that $37 \mathrm{mM}$ of $\mathrm{MgCl}_{2}$ reduced degradation rates of

21 trichloroethylene (TCE) to $2 \%$ of the original rate. They found that the low levels of Mn

22 present after replacing the packed bed reactor and rinsing the remaining components was

23 sufficient to reduce the degradation rate to $11 \%$ of its control value. Brezova et al. [52] found

24 a much smaller effect on the degradation of phenol such that $0.28 \mathrm{mM}$ of $\mathrm{Mg}$ increased the 
1 half-life from 14 to 17 minutes. The redox potential of the $\mathrm{Mn}^{2+} / \mathrm{M}^{0}$ couple is $-1.185 \mathrm{~V}$ [55]

2 (Figure 1), which is significantly more negative than the conduction band of $\mathrm{TiO}_{2}$ even at

3 high $\mathrm{pH}$, indicating that $\mathrm{Mn}^{2+}$ cannot be directly reduced by $\mathrm{TiO}_{2}$ [56]. However, $\mathrm{Mn}^{2+}$ can

4 be oxidized by $\mathrm{TiO}_{2}$ to $\mathrm{Mn}^{3+}$ by holes. The presence of electron acceptors such as oxygen or

5 oxalate allows for the formation of $\mathrm{MnO}_{2}$ [57] or $\mathrm{Mn}^{0}$ [58] on the surface of titanium. Once

6 deposited, these species are stable and difficult to remove. In the absence of these species,

$7 \mathrm{Mn}^{2+}$ shows no reduction by or deposition on $\mathrm{TiO}_{2}[56,59]$.

8 As well as $\mathrm{Mn}$ ions in solution, $\mathrm{MnO}_{2}$ is common in many natural water systems due to 9 mineral leaching and can have a large effect on the efficacy of $\mathrm{TiO}_{2}$. Several studies [18, 60, 61] have reported a large change in the breakdown rate of phenol [18] and methyl orange [60] in the presence of $\mathrm{MgO}_{2}$ particles (largest dimension ranging from 200-450 nm) at $20 \mathrm{mg} / \mathrm{L}$ (0.23 mM). Core-shell type structures were formed as small $\mathrm{TiO}_{2}$ particles $(25-30 \mathrm{~nm})$ deposited on the surface of the larger $\mathrm{MnO}_{2}$ particles due to electrostatic attraction. Different phases of $\mathrm{MnO}_{2}$ led to different reductions in photocatalytic activity with $\delta-\mathrm{MnO}_{2}>\alpha-$ $\mathrm{MnO}_{2}>\beta-\mathrm{MnO}_{2}$. A number of factors contributed to this large effect. $\mathrm{MnO}_{2}$ absorbs widely in the visible and near UV spectrum and can optically screen the $\mathrm{TiO}_{2}$ surface thereby reducing the number of photons available to generate charge pairs [60]. The extent of the absorption is dependent on the $\mathrm{MnO}_{2}$ phase matching the effects on photocatalytic activity with $\delta$ $\mathrm{MnO}_{2}>\alpha-\mathrm{MnO}_{2}>\beta-\mathrm{MnO}_{2} . \mathrm{MnO}_{2}$ also introduces a series of bands within the band gap of $\mathrm{TiO}_{2}$ which leads to an increased recombination rate. Furthermore, the $\mathrm{MnO}_{2} / \mathrm{TiO}_{2}$ interface may increase the band gap energy, leading to a blue shift in the absorption edge and effectively reducing the absorption further. Similar effects were reported by Rao and Chaturvedi [62] with P25 immobilized on pebbles made of minerals high in $\mathrm{MnO}_{2}$. reported a $20 \%$ and $35 \%$ increase in the breakdown of toluene at $\mathrm{pH} 3$ and 7 with no change 
1 at pH 5. Chen et al. [64] reported a significant increase for the breakdown of 2-CP at pH 3.

2 This effect was assigned to the redox couple of $\mathrm{Mn}^{3+} / \mathrm{Mn}^{2+}$ acting to decrease recombination

3 or through the formation of reactive metallo-organic complexes. At this time, it is not clear

4 what parameters determine whether manganese will act as a foulant or as a promoter but the

5 majority of reports suggest that fouling is the more common effect.

\section{$6 \quad 3.3 .3 \quad$ Chromium}

7 Much like $\mathrm{Mn}, \mathrm{Cr}(\mathrm{III})$ has been shown to greatly reduce photocatalytic activity, even at 8 concentrations as low as $1 \mu \mathrm{M}$. Examples of the effect on $\operatorname{Cr}(\mathrm{III})$ are shown in Table 9.

9 Except at high $\mathrm{pH}$, the direct reduction of $\mathrm{Cr}^{3+}$ does not readily occur on $\mathrm{TiO}_{2}$. Therefore, 10 unlike Cu or some other metals, Cr does not appear to deposit onto the surface as $\mathrm{Cr}^{0}$ nor is it 11 converted to $\mathrm{Cr}^{6+}$. Instead it appears to simply displace $\mathrm{H}^{+}$on the surface titania, as 12 demonstrated by a drop in $\mathrm{pH}$ on the addition of $\mathrm{Cr}$ to slurry of $\mathrm{TiO}_{2}$ [52] or precipitate as $13 \mathrm{Cr}(\mathrm{OH})_{3}[58,65]$. It has been suggested that fouling by $\mathrm{Cr}$ is due to a combination of surface 14 blockage and increased recombination [48]. The presence of $\operatorname{Cr}(\mathrm{VI})$ can cause an initial increase in the oxidation of organic compounds by acting as an electron scavenger, increasing the charge separation and reducing recombination [66]. However, reduction of Cr(VI) yields

17 Cr(III) by the following reactions:

$$
\begin{gathered}
\mathrm{Cr}_{2} \mathrm{O}_{7}^{2-}+14 \mathrm{H}^{4}+6 e^{-} \rightarrow 2 \mathrm{Cr}^{3+}+7 \mathrm{H}_{2} \mathrm{O}\left(\mathrm{E}^{\circ}=1.36 \mathrm{~V}\right) \\
\mathrm{CrO}_{4}^{2-}+8 \mathrm{H}^{+}+3 e^{-} \rightarrow \mathrm{Cr}^{3+}+4 \mathrm{H}_{2} \mathrm{O}\left(\mathrm{E}^{\circ}=1.350 \mathrm{~V}\right) \\
\mathrm{CrO}_{4}^{2-}+4 \mathrm{H}_{2} \mathrm{O}+3 e^{-} \rightarrow \mathrm{Cr}(\mathrm{OH})_{3}+5 \mathrm{OH}^{-}\left(\mathrm{E}^{\circ}=-0.13 \mathrm{~V}\right)
\end{gathered}
$$

18 Reaction (16) is predominant at acidic $\mathrm{pH}$, while reaction (17) is predominant at neutral $\mathrm{pH}$, 19 and reaction (18) is under basic conditions [67]. The produced $\mathrm{Cr}^{3+}$ can then foul the titanium 20 surface as described above. These reactions also allow for Cr to initially act as a promoter for 21 some reactions by acting as an electron scavenger [66, 68]. 


\section{$1 \quad 3.3 .4 \quad$ Copper}

2 Depending on the target and concentration, copper can act as either a foulant or a promoter.

3 At low concentrations $(<50 \mu \mathrm{M})$ copper generally acts as a promoter, while at higher levels, it

4 acts as a foulant. Generally, a peak reaction rate occurs at concentrations in the order of 1-10

$5 \mu \mathrm{M}$ then slowly decreases, eventually reaching a rate less than the original. Table 10 shows

6 examples of the concentration where the peak reaction was observed as well as the

7 concentration at which inhibition began.

8 Copper can cause inhibition due to a number of mechanisms. As with other metals, Cu can be

9 deposited onto the $\mathrm{TiO}_{2}$ surface in the form of $\mathrm{Cu}^{0}$, $\mathrm{CuO}$, or $\mathrm{Cu}_{2} \mathrm{O}$ [69-71]. Other precipitates have been reported including copper carbonate and sulphate compounds [63, 72]. Aside from

11 the blocking of active sites, the deposition of copper compounds results in a much more 12 reflective surface resulting in reduced illumination of the surface of $\mathrm{TiO}_{2}[52,69]$. Copper is 13 also known to form metal-ligand complexes with a wide array of compounds. These complexes appear to have different effects on different targets.

15 A number of mechanisms have been suggested for how $\mathrm{Cu}^{2+}$ ions act as a promoter, aside 16 from simple electron trapping and homogenous catalysis. Lam et al. $[73,74]$ argued that 17 targets form complexes with $\mathrm{Cu}^{2+}$ ions followed by the transfer of an electron from the target to copper to form $\mathrm{Cu}^{+}$, which is later regenerated by photogenerated holes. For the studied targets, the $\mathrm{Cu}$ complexes showed higher adsorption onto $\mathrm{TiO}_{2}$ than uncomplexed $\mathrm{Cu}$ which will also lead to higher breakdown rates. Du et al. [51] have argued for the reaction of $\mathrm{Cu}^{2+}$ with superoxide radicals. This results in both electron trapping and the formation of $\mathrm{H}_{2} \mathrm{O}_{2}$, which are responsible for the increase in breakdown rates.

\section{$23 \quad 3.3 .5 \quad$ Iron}

24 Like copper, iron is a promoter at lower concentrations $(<1 \mathrm{mM})$ but can act as an inhibitor at higher concentrations (> 10mM) [63]. Unlike copper, where rates quickly peak, iron shows a 
1 much larger plateau of peak promotion before rates begins to decrease $[48,52,75,76]$. In

2 addition to the other promotion mechanisms previously described, certain iron hydroxides

3 can undergo photolysis by light in the 200-300 nm range to produce hydroxide radicals [77-

4 79]. This large peak area means that in most studies iron acts as a promoter rather than an

5 inhibitor in the ranges studied.

\section{$6 \quad$ 3.3.6 Nickel}

7 In general, nickel exhibits similar behaviour to copper but with a $\mathrm{pH}$ dependence. Aside from 8 simple direct reduction from $\mathrm{Ni}^{2+}$ to $\mathrm{Ni}^{0}$, at $\mathrm{pH}>9$ nickel is capable of depositing nickel 9 oxides onto the $\mathrm{TiO}_{2}$ surface based on the following reaction [17, 37, 55]:

$$
2 \mathrm{Ni}^{2+}+2 \mathrm{O}_{2}+2 \mathrm{H}_{2} \mathrm{O} \rightarrow 2 \mathrm{NiO}_{2}+4 \mathrm{H}^{+}
$$

10 A number of indirect reactions can also occur resulting in the deposition of nickel such as the reduction by carbonate radicals [80, 81]. Similar to copper, nickel is also capable of forming complexes with other molecules and altering reactions [82]. But unlike copper, there appears to be no reports on the acceleration of reactions in the presence of nickel due to complexation.

\subsubsection{Others}

16 Brezova et al. [52] reported that the presence of approximately $1 \mathrm{mM}$ of $\mathrm{Co}^{2+}$ caused the 17 degradation rate of phenol to drop to $66 \%$ of the baseline. Similarly, Kormann et al. [25] reported a drop of $50 \%$ for $1 \mathrm{mM}$ of $\mathrm{Co}^{2+}$ for the breakdown of chloroform. In both cases the decrease was attributed to the short-circuit reactions, which are possible as the redox potential is $-0.28 \mathrm{~V}$. Additionally, both of these tests were performed at $\mathrm{pH}$ near 7 which is above the

21 PZC of $\mathrm{TiO}_{2}$ allowing for significant adsorption of the positive cobalt ions.

Although lead is capable of being reduced by $\mathrm{TiO}_{2}$, the process is slow in the absence of 23 electron donors, likely due to poor adsorption [56, 83-86]. This results in $\mathrm{Pb}^{2+}$ having little

24 effect on the degradation of targets by $\mathrm{TiO}_{2} . \mathrm{Zn}^{2+}$ has also been examined and has not shown 
1 to affect the photodegradation of glyphosate [87], dichlorvos [38], phenol [52], and 2-

2 chlorophenol [88] among others. $\mathrm{TiO}_{2}$ cannot directly photo reduce $\mathrm{Zn}^{2+}$ until $\mathrm{pH} \sim 12$ as the

3 reduction potential is too high [55], but it can be reduced by indirect methods by radicals

4 such as formate [89]. In contrast to these studies, Kormann et al. [25] reported a 60\%

5 decrease in the degradation of chloroform at $\mathrm{pH}$ 7. The mechanism by which this inhibition

6 occurred was not adequately explained however but it is may be due to the absorption of the

$7 \quad \mathrm{Zn}^{2+}$ to the surface.

\section{THE EFFECTS OF ORGANICS}

\section{$9 \quad 4.1$ Alcohols}

10 Low molecular weight alcohols can act as powerful radical scavengers as can been seen by

11 the reaction rates listed in Table 11. Unlike anion radicals, alcohols exhibit almost no

12 reactivity towards targets making their scavenging even more effective. The ability of short

13 chain alcohols to deactivate hydroxide radicals is sufficiently strong that they are used as to

14 help elucidate the degradation mechanism for a given target by all but stopping any

15 hydroxide radical mediated pathways [90, 91]. In contrast to ions, alcohols are susceptible to

16 breakdown by $\mathrm{TiO}_{2}[92]$.

17 The degradation rate of carbofuran in the presence of isopropanol (at 100 times the 18 concentration of carbofuran) was reduced by $~ 50 \%$ [90]. A 70\% decrease in the breakdown

19 of imazalil was reported [93] for similar ratios of methanol and isopropanol. A range of concentrations were examined and a maximum rate was found for a ratio of $~ 100: 1$

21 (alcohol:target). A reduction of $\sim 80 \%$ in the breakdown of bisphenol-A for a ratio of 633

22 methanol to BPA has been shown [5] and even 1\% ethanol reduced the breakdown rate by $2340 \%$ with similar results seen for methanol, isopropanol and butanol [94]. A close to 90\% 24 reduction was reported [95] for the breakdown of clopyralid in a 1\% ethanol solution. In 
1 contrast, methanol or isopropanol had relatively little effect on the breakdown of Acid

2 Orange 7 [30] and similar results have been shown for flumequine [31].

3 Alcohols can have a large effect on the breakdown rates for targets where hydroxyl attack is

4 the primary pathway. However, for targets that breakdown by other routes, such as direct

5 hole attack, alcohols show little effect.

$6 \quad 4.2$ Humic and fulvic acid

7 The natural organic matter (NOM) in many waters can inhibit the breakdown of targets by

8 three main methods: site blockage, hydroxyl scavenging, and light absorption. Because of

9 these multiple methods, NOM can act as a strong inhibitor for a wide arrange of targets.

10 Humic acid and other dissolved organic matter have been shown to strongly adsorb to the

11 surface of $\mathrm{TiO}_{2}$, primarily under acidic conditions [96-99] due to charge effects. Adsorption

12 of this matter blocks the adsorption of other species including targets, water, and oxygen

13 preventing the generation of radicals. Dissolved organic matter (DOM) can also act as a

14 scavenger for radicals and holes. This scavenging will result in the DOM being broken down

15 by $\mathrm{TiO}_{2}$ into smaller molecules, and $\mathrm{TiO}_{2}$ has been used for this express purpose in some

16 studies [100-102]. As the purpose of most systems is to breakdown anthropogenic

17 compounds, this is seen as inhibition rather than a desired result. Aside from simple site

18 blockage and competitive reactions, humic acid also absorbs UV light, reducing the effective

19 illumination of the catalyst.

20 The effect of humic substances was examined in the breakdown of 1,2,3-trichlorobenzene 21 and 4-chlorophenol [91]. At $50 \mathrm{mg} / \mathrm{L}$ of humic matter, the degradation rate of 123-TCB was 22 reduced by approximately 75\% and 4-CP by 50\%. 4-CP was also tested in farm runoff water 23 containing an estimated $50 \mathrm{mg} / \mathrm{L}$ humic substances and the rate reduced to $25 \%$. This 24 dependence on the composition of the DOM has also been reported in other studies [103]. In 
1 the case of quinolone [99], this screening effect was responsible for the majority of the

2 reduction in breakdown. At low concentrations ( $\sim \mathrm{mg} / \mathrm{L})$, a slight increase in the removal

3 rate was observed, attributed to weak binding of quinoline to humic acid adsorbed on the

4 surface of $\mathrm{TiO}_{2}$, which increased the rate by increasing the local concentration of quinoline

5 near the site of radical generation. However, this effect is relatively weak and is rapidly

6 surpassed by the UV blocking effect. A 40\% reduction was observed in the breakdown of

7 carbamazepine in the presence of $0.5 \mathrm{mg} / \mathrm{L}$ NOM and near complete inhibition at $7 \mathrm{mg} / \mathrm{L}$

8 [104] and similar results were observed for iomeprol. Hombikat UV100 (a purpose-designed

9 photocatalytic $\mathrm{TiO}_{2}$ ) showed significantly less inhibition from NOM than $\mathrm{P} 25 \mathrm{TiO}_{2}$, which

10 was attributed to the larger surface area reducing the impact of competitive adsorption. This

11 finding, coupled with low levels of light absorption indicated that site blockage was the 12 primary inhibition mechanism in this case.

\section{$13 \quad 5$ SUPPORTS}

$14 \mathrm{TiO}_{2}$ can be used as either a suspension or as a thin film placed on a support. These films can 15 be made of immobilized particles such as P25 or made from precursors chemicals. In all 16 cases, behind this film is a supporting material typically made of glass, metals, or polymers.

17 While ideally these supports would have no effect on films, it appears from research that the 18 choice of support can affect the performance of a film, primarily by the migration of ions 19 from the support to the film.

$20 \quad 5.1$ Glass

21 Some ions, such as $\mathrm{Na}^{+}$and $\mathrm{Ca}^{2+}$, are known to migrate from glasses into $\mathrm{TiO}_{2}$ films during 22 calcination [105-108]. The presence of these ions can lead to films with larger crystallite 23 sizes and delay the formation of the anatase phase until higher calcination temperatures. Both 24 of these factors decrease the efficiency of the resultant catalyst. However, coating the support 
1 with a layer of $\mathrm{SiO}_{2}$ [107] or $\mathrm{SiN}_{\mathrm{x}}$ [109] can prevent the migration of these ions into the $\mathrm{TiO}_{2}$

2 film.

\section{$3 \quad 5.2$ Metals}

4 Metals provide stable and strong supports for $\mathrm{TiO}_{2}$ catalysts. Various scratch and tape testing

5 of $\mathrm{TiO}_{2}$ films reveal little or no damage on stainless steel [110, 111], silicon [112], or

6 aluminium [113] supports. Some metals cause contamination (resulting in a reduced

7 performance) when used as a substrate for $\mathrm{TiO}_{2}$ films. Aluminium supports [114] coated with

$8 \mathrm{TiO}_{2}$ using sol-gel techniques (1 to 7 coating cycles of $\sim 200 \mathrm{~nm}$ thickness) showed

9 aluminium migration into all layers, occupying approximately 3 atomic \% of the surface for

10 one coating cycle and $0.65 \%$ for six coating cycles. In pristine coatings, titanium on the

11 surface was present as $\mathrm{Ti}^{4+}$ but after six photocatalytic cycles this decreased to $62 \%$ (for one

12 coating cycle films) and $85.7 \%$ (for three coating cycle films) but interestingly was

13 maintained at $100 \% \mathrm{Ti}^{4+}$ for the six coating cycle films. The change was almost entirely to

$14 \mathrm{Ti}^{3+}$, and it was proposed that these sites acted as recombination centres by trapping electrons

15 [115]. Stainless steel has also been shown to release ions into coatings. Fe, Cr, and Mn have

16 been found in sol-gel coatings of $\mathrm{TiO}_{2}$ [116] and $\mathrm{Fe}, \mathrm{Cr}$, and $\mathrm{Ni}$ have been reported in

17 atmospheric pressure chemical vapour deposition (CVD) grown films on stainless steel [117].

18 The effect of these ions on the structure or photocatalytic activity of $\mathrm{TiO}_{2}$ has not been

19 studied in these situations.

$20 \quad 5.3$ Other

21 Naturally occurring rocks have been used as supports for $\mathrm{TiO}_{2}$ films, but the composition of

22 the rocks can affect the efficiency of the resulting films. Three types of pebbles were

23 examined for the degradation of Reactive Black 5 by immobilized P25 $\mathrm{TiO}_{2}: \mathrm{MnO}_{2}$ rich,

24 quartz with significant amounts of $\mathrm{FeOOH}$, and quartz/Fe oxide rich [118]. $\mathrm{MnO}_{2}$-rich

25 pebbles showed significantly less activity than the others, presumably due to the effects of 
$1 \mathrm{MnO}_{2}$ (as noted above) as well as the dissolution of small amounts of magnesium ions into

2 solution. The Fe rich pebbles were more efficient than the $\mathrm{MnO}_{2}$ rich pebbles but still much

3 less so than the quartz rich. Films of $\mathrm{TiO}_{2}$ on ceramics containing $\mathrm{Al}_{2} \mathrm{O}_{3}$ yielded similar

4 results to those on aluminium alloys [119]. Aluminium ions migrated into the film and

5 replaced some $\mathrm{Ti}^{4+}$ sites with $\mathrm{Al}^{3+}$, which acted as recombination sites and decreased the 6 number of free charges in the film.

\section{$7 \quad 6 \quad$ BIOFOULING}

8 Although $\mathrm{TiO}_{2}$ can inhibit the growth of algae [120-122], $\mathrm{TiO}_{2}$ films may be susceptible to 9 algal growth over time. P25 on pumice stones formed a film of algae after less than two weeks, which prevented further use [123]. A number of factors may have made these films susceptible to algal growth; they were used outdoors, exposed to sunlight and air which may have influenced the ability of algae to grow on the $\mathrm{TiO}_{2}$ surface. The films were illuminated

13 from the catalyst side so once a film of a certain thickness had formed it may have blocked

14 further light from reaching the catalyst. No other studies have reported this problem and so 15 the potential impact of algae remains unknown.

\section{RELEASE OF CATALYST}

17 In the long term use of immobilized $\mathrm{TiO}_{2}$ as a photocatalyst, the potential loss of the material 18 from the film should be taken into account. This issue not only affects the lifetime of the catalyst but is also an important factor in determining its environmental safety. Generally, fresh and well prepared films possess strong adhesion. Results from adhesion tests are

21 summarized in Table 12. Some studies have reported delamination or other loss of $\mathrm{TiO}_{2}$ films

22 prepared from particle slurries [123-125]. Loss of such material was dependant on $\mathrm{pH}$ and the

23 ionic strength of the medium [124]. Delamination occurred primarily when the $\mathrm{pH}$ was less 
1 than 3 or greater than 11 or when the ionic strength was above $0.5 \mathrm{M}$. It was suggested that

2 the high surface charge (either negative or positive) on the $\mathrm{TiO}_{2}$ created a repulsive force

3 large enough to cause the release of $\mathrm{TiO}_{2}$ from the silica support. An alternative explanation

4 was acid or base catalyzed cleavage of Si-0-Ti bonds. The adhesion of immobilized P25 as

5 well as sol-gel derived coatings on glass beads was examined during the oxidation of formic

6 acid [126]. After $50 \mathrm{~h}$ of use, the P25 coatings had released 7\% of the coating and the sol-gel

$7 \quad 33 \%$. Silica grains were also used as supports. These released 21\% of the P25 coatings and

$852 \%$ for sol-gel coatings. Most of the loss appeared to be in the form of small particles rather

9 than large areas of delamination.

10 A number of other studies using immobilized P25 have not reported any loss or delamination

11 but were within the 'safe' region established by Peill and Hoffmann [113, 127, 128]. In

12 contrast, Rao et al. [123] examined thin film reactors based on P25 on pumice and PC500 on

13 cellulose, operating at near neutral $\mathrm{pH}$. They aged both for up to 4 weeks with a $2.5 \mathrm{mM}$

14 solution of Acid Orange-7 which was replaced when decoloured. The reaction rates of both were shown to significantly decline with increasing time. Microscopy revealed that in both cases there had been a significant loss of $\mathrm{TiO}_{2}$ from the surfaces.

17 A $~ 40 \%$ loss of a plasma CVD coating on glass beads after a single use in a fluidized bed reactor was observed [129] due to uniform erosion (rather than delamination). The release of $\mathrm{TiO}_{2}$ from Pilkington Activ, which is a CVD deposited film [130], as well as an experimental coating composed of $50 \% \mathrm{TiO}_{2}$ nanoparticles embedded in a siliceous matrix were examined 21 [131]. Water, spiked in some cases with humic acid, $\mathrm{NaCl}$, or both, was recirculated through a glass slide reactor for 4 weeks. The Ti content of the water was then measured to give the cumulative release of $\mathrm{TiO}_{2}$ over the 4 weeks. $\mathrm{TiO}_{2}$ was released at cumulative levels of $10-$ $100 \mu \mathrm{g} / \mathrm{l}$ for the Pilkington Activ and from $0-150 \mu \mathrm{g} / \mathrm{l}$ for the experimental coatings. The amount appeared to depend on the composition of the water; deionized water showed very 
1 little release, but with the addition of $10 \mathrm{~g} / \mathrm{l} \mathrm{NaCl}, 3 \mathrm{mg} / \mathrm{l}$ humic acid, or both, there was a

2 large increase in the amount of titanium in the outflow water. Similarly, a larger amount of Ti

3 was released when the films were exposed to UVA illumination compared with those left in

4 the dark. The levels are somewhat similar to those reported in treated wastewater [132, 133]

5 and an order of magnitude less than those report for the release of Ti from exterior paints

6 [134], likely due to stronger adhesion in photocatalytic coatings [131].

7 Sol-gel derived films have been fabricated on pre-treated titanium foils [135]. Treatment by 8 either sonication in acetone or boiling in $10 \%$ oxalic acid was examined. Films were 9 immersed in deionized water and periodically tested for the breakdown of benzamide under 10 UV light. Acetone treated samples rapidly lost photocatalytic activity, with less than $15 \%$ 11 remaining after 60 days of immersion. The loss of activity was explained by the large loss of $12 \mathrm{TiO}_{2}$ material found when the foils were examined by electron microscopy. Oxalic acid 13 treated samples showed a much more gradual loss, appearing to stabilize after 200 days with 14 more than $70 \%$ activity remaining. A suggested explanation for this was that water was able to penetrate the acetone treated film and react with the titanium support to form a new $\mathrm{TiO}_{2}$ layer causing the detachment of the coating from the support. The oxalic acid coating was much denser and so water was not able to reach the support resulting in a more stable film.

\section{REACTION BY-PRODUCTS}

19 In theory, $\mathrm{TiO}_{2}$ should completely mineralize many targets but this is not always achieved in practice. Even when the reactions are allowed to precede to full mineralization a number of degradation by-products are temporarily created due to the multiple steps required. Some byproducts (including simple ions, liberated anions, or small organics) can act as foulants or inhibitors. For example, methylene blue produces sulphate ions on discoloration and 4- 
1 the $\mathrm{TiO}_{2}$ surface, preventing the adsorption of other species, and possibly produce screening

2 effects [123, 137]. By-products may be implicated in a change in the colour of the catalyst

3 after use. $\mathrm{TiO}_{2}$ films on glass exposed to methylene blue in deionized water were fully

4 deactivated after $96 \mathrm{~h}$, which was attributed to the various reaction by-products [138]. During

5 the degradation of trichloroethylene [139], the by-products dichloroacetate, trichloroacetyl

6 chloride and trichloroacetate were formed and were all resistant to further degradation. Other

7 researchers have reported overall efficiency losses were reduced with successive cycles [140]

8 and a significant increase in the breakdown of ibuprofen at later cycles.

9 It is possible that harmful substances may be generated from certain targets. These can result from the breakdown of larger targets into simpler components or from reactions with other

11 species in the water matrix. For example, the presence of chloride leads to the production of

$12 \mathrm{Cl} \cdot$ radicals. While $\mathrm{Cl} \cdot$ is much less reactive than $\mathrm{OH} \cdot$, it is still capable of oxidizing targets to 13 produce chlorinated compounds, many of which are harmful and persistent in the 14 environment [141]. In particular, there appears to be the possibility for the formation of significant amounts of trihalomethanes such as chloroform or bromoform, with haloacetic acids being a more minor concern [142-144]. Most of these compounds, however, are susceptible to further photocatalytic breakdown, and their release can be prevented by ensuring a sufficiently long reaction time [144, 145].

\section{REGENERATION}

The ability to regenerate a fouled catalyst is an important consideration to ensure the

21 economic viability of many processes. A number of techniques have been used successfully

22 for various foulants. These methods and their underlying mechanisms are listed in Table 13.

23 Which method is best depends on the nature of the foulants. Loosely adsorbed foulants such

24 as chloride or nitrate can be washed with clean water [17, 47]. More strongly adsorbed 
1 pollutants such as phosphate may require an acidic or basic rinse to remove them. The change

2 in $\mathrm{pH}$ either alters the solubility of the foulant or transforms it into a soluble form.

3 Illumination can also be used to regenerate an aged photocatalyst where the primary fouling 4 species are susceptible to degradation $[138,146]$. In this case the catalyst is placed in clean 5 water and illuminated for an appropriate time. For photodeposited copper, oxidation by 6 oxygen has been used to form a dissolved ionic species [72, 147]. For example:

$$
2 \mathrm{Cu}^{0}+2 \mathrm{H}^{+}+\mathrm{O}_{2} \rightarrow \mathrm{Cu}^{2+}+2 \mathrm{H}_{2} \mathrm{O}
$$

7 As an alternative method or as enhancement to this procedure, an electric current can be 8 applied to accelerate the reaction [69].

9 Fouled catalysts may be regenerated by heating. This occurs through two primary 10 mechanisms; desorption of the adsorbed species due to the increased energy, and pyrolysis of 11 compounds to form less strongly adsorbed species. For some contaminants, particularly 12 inorganic ions, heating above $\sim 400{ }^{\circ} \mathrm{C}$ can result in the contaminant being integrated into the $13 \mathrm{TiO}_{2}$ structure. This is a commonly used method for doping and can transform an inhibitor 14 such as $\mathrm{Mn}^{2+}$ into a promoter [148].

15 The regeneration P25 photocatalyst fouled by the degradation of phthalic acid was examined 16 [149] using three methods: a water/methanol rinse, thermal treatment at $350^{\circ} \mathrm{C}$, and treatment 17 with $\mathrm{H}_{2} \mathrm{O}_{2}$. The solvent wash method had little effect in the regeneration of the catalyst. 18 Thermal treatment returned the catalyst to approximately $50 \%$ of the base rate while $\mathrm{H}_{2} \mathrm{O}_{2}$ 19 treatment completely regenerated the catalyst. Treatment with $\mathrm{H}_{2} \mathrm{O}_{2}$ facilitated the breakdown 20 of recalcitrant carboxylic acids adsorbed on catalyst surface. Carbonaro et al. [6] examined 21 the breakdown of acetaminophen, carbamazepine, iopromide, and sulfamethoxazole in wastewater effluent compared with a buffered electrolyte solution. All four targets showed a

23 significant reduction (between $40 \%$ and $80 \%$ ) in their breakdown rate when the water matrix 
1 was switched to the effluent. However, on switching to clean electrolyte the breakdown rates

2 fully recovered for all targets.

\section{PREVENTION}

4 There are a number of prevention methods reported to date. Control of the $\mathrm{pH}$ is one of the

5 oldest methods. Foulants such as chloride, carbonate and phosphate all show pH dependence

6 in their mechanism. Reducing the $\mathrm{pH}$ in groundwater with significant levels of carbonate

7 from 7.2 to $\sim 5$ with $\mathrm{HCl}$ significantly improved the breakdown rate of TCE by as much as

$8400 \%$ [7]. However, altering the $\mathrm{pH}$ may also affect the breakdown of targets and so care

9 should be taken to find the optimum value for a combination of matrix species and targets.

10 Activated carbon, already widely used in water purification, can be used to remove DOM that

11 would otherwise inhibit the breakdown of the target compounds. Passing wastewater effluent

12 through a GAC filter halved the inhibition for acetaminophen [6] but made little difference

13 for the effects of carbamazepine, iopromide, and sulfamethoxazole.

14 Metals such as Ag or Pt may be deposited onto the surface of the $\mathrm{TiO}_{2}$ to prevent fouling.

15 The degradation of Sirius Gelb GC using silver-doped anatase particles was examined [150].

16 The bare and silver-dope particles were exposed to $250 \mathrm{mg} / \mathrm{L}$ of $\mathrm{NaSO}_{4}{ }^{-}, \mathrm{Na}_{2} \mathrm{C}_{2} \mathrm{O}_{4}, \mathrm{NaHPO}_{4}{ }^{-}$,

$17 \mathrm{NaCH}_{3} \mathrm{COO}, \mathrm{NaSO}_{3}, \mathrm{NaCl}, \mathrm{NaNO}_{3}, \mathrm{Na}_{2} \mathrm{CO}_{3}$, and sodium citrate. The Ag-TiO ${ }_{2}$ material

18 showed lower reduction in the presence of all salts except $\mathrm{NaCl}$ and $\mathrm{NaNO}_{3}$. In the case of

$19 \mathrm{NaCl}$, a slight increase in the degradation was seen on bare $\mathrm{TiO}_{2}$ as opposed to a slight

20 decrease in $\mathrm{Ag}-\mathrm{TiO}_{2}$. Similarly, the deposition of $\mathrm{Al}(\mathrm{III})$ onto the surface of $\mathrm{P} 25$ greatly

21 reduced the fouling by salicylic acid [151]. This may be attributed to a combination of

22 enhanced breakdown leading to fewer inhibitory species as well as the metal acting as a poor

23 adsorbent site for salicylic acid and its breakdown products. 
1 Some reactor designs are also immune to certain forms of inhibition or fouling. For example,

2 particle aggregation cannot occur in reactors where the $\mathrm{TiO}_{2}$ has been immobilized onto a

3 support as the particles are not free. An immobilized film illuminated from the rear side of

4 the support is also relatively immune to inhibition due to loss of light absorption as the light

5 does not pass through the solution before illuminating the catalyst.

\section{$6 \quad 11$ CONCLUSIONS}

7 The compounds present in photocatalytic systems can have a significant effect on the

8 efficiency of the process. Of particular importance is the presence of carbonate ions, as not

9 only are they strong inhibitors for many targets but are also extremely common in both natural and artificial waters. Mn and $\mathrm{Cr}$ also appear to be powerful inhibitors though their

11 presence is less common. Even in the absence of inhibitors in the aqueous matrix prior to

12 photocatalysis, various reaction products are capable of fouling the catalyst, in some cases to

13 the extent of almost complete deactivation. Some of these reaction by-products can be toxic

14 somewhat defeating the purpose of the system. While there are methods that can be used to

15 reduce the impact of certain foulants, these methods cannot always be used as they may

16 themselves cause a reduction in the breakdown of target compounds. For example, the effect

17 of carbonate can be reduced by acidification of the water matrix but for some targets this can

18 also cause a decrease in the breakdown rate of targets or increase in the inhibition by another

19 inhibitor present. Further work is needed on methods to prevent fouling that will apply to a

20 wise range of foulants and targets. Some methods have been proposed such as metal coating

21 of the catalyst or pretreatment by activated carbon however more work needs to be done to

22 determine the efficacy of this methods with more foulants and targets. This means that one of

23 the most powerful tools to deal with inhibition is to take its effects into account in the system

24 design and ensure that the reaction time, regeneration cycles, catalyst loading or active 


\section{ACKNOWLEDGMENTS}

6 This research was funded by the Cooperative Research Centre for Contamination Assessment

and Remediation of the Environment (CRC CARE).

\section{REFERENCES}

[1] A. Fujishima and K. Honda, "Electrochemical Photolysis of Water at a Semiconductor Electrode," Nature, vol. 238, no. 5358, pp. 37-38, 1972.

[2] M. Formenti, F. Juillet, and S. J. Teichner, "PHOTOOXIDATION OF PARAFFINS AND OLEFINS IN PRESENCE OF ANATASE AT AMBIENT TEMPERATURE," COMPTES RENDUS HEBDOMADAIRES DES SEANCES DE L ACADEMIE DES SCIENCES SERIE C, vol. 270, no. 2, pp. 138-141, 1970.

[3] N. Djeghri, F. Juillet, M. Formenti, and S. J. Teichner, "Photointeraction on the surface of titanium dioxide between oxygen and alkanes," Faraday Discussions of the Chemical Society, vol. 58, no. 0, pp. 185-193, 1974.

[4] J. Fenoll, P. Flores, P. Hellín, C. M. Martínez, and S. Navarro, "Photodegradation of eight miscellaneous pesticides in drinking water after treatment with semiconductor materials under sunlight at pilot plant scale," Chemical Engineering Journal, vol. 204-206, pp. 54-64, 2012.

[5] P. S. Yap and T. T. Lim, "Effect of aqueous matrix species on synergistic removal of bisphenol-A under solar irradiation using nitrogen-doped TiO2/AC composite," Applied Catalysis B: Environmental, vol. 101, no. 3-4, pp. 709-717, 2011.

[6] S. Carbonaro, M. N. Sugihara, and T. J. Strathmann, "Continuous-flow photocatalytic treatment of pharmaceutical micropollutants: Activity, inhibition, and deactivation of TiO2 photocatalysts in wastewater effluent," Applied Catalysis B: Environmental, vol. 129, pp. 112, 2013.

[7] M. S. Mehos and C. S. Turchi, "Field testing solar photocatalytic detoxification on TCE contaminated groundwater," Environmental progress, vol. 12, no. 3, pp. 194-199, 1993.

[8] A. Mills and S. L. Hunte, "An overview of semiconductor photocatalysis," Journal of photochemistry and photobiology. A, Chemistry, vol. 108, no. 1, pp. 1-35, 1997.

[9] M. Litter, "Heterogeneous photocatalysis Transition metal ions in photocatalytic systems," Applied Catalysis B: Environmental, vol. 23, no. 2-3, pp. 89-114, 1999.

[10] H. H. Mohamed and D. W. Bahnemann, "The role of electron transfer in photocatalysis: Fact and fictions," Applied Catalysis B: Environmental, vol. 128, pp. 91-104, 2012.

[11] A. Fujishima, X. Zhang, and D. Tryk, "TiO2 photocatalysis and related surface phenomena," Surface Science Reports, vol. 63, no. 12, pp. 515-582, 2008.

[12] M. D. Ward, J. R. White, and A. J. Bard, "Electrochemical investigation of the energetics of particulate titanium dioxide photocatalysts. The methyl viologen-acetate system," Journal of the American Chemical Society, vol. 105, no. 1, pp. 27-31, 1983. 
[13] T. Watanabe, A. Fujishima, O. Tatsuoki, and K.-I. Honda, "pH-Dependence of Spectral Sensitization at Semiconductor Electrodes," Bulletin of the Chemical Society of Japan, vol. 49, no. 1, pp. 8-11, 1976.

[14] Y. Zhang, Y. Chen, P. Westerhoff, and J. Crittenden, "Impact of natural organic matter and divalent cations on the stability of aqueous nanoparticles," Water Res, vol. 43, no. 17, pp. 4249-57, 2009.

[15] S. Ottofuelling, F. Von Der Kammer, and T. Hofmann, "Commercial titanium dioxide nanoparticles in both natural and synthetic water: comprehensive multidimensional testing and prediction of aggregation behavior," Environmental Science \& Technology, vol. 45, no. 23, pp. 10045-52, 2011.

[16] S. Mozia, M. Tomaszewska, and A. W. Morawski, "Decomposition of nonionic surfactant in a labyrinth flow photoreactor with immobilized TiO2 bed," Applied Catalysis B: Environmental, vol. 59, no. 3-4, pp. 155-160, 2005.

[17] R. A. Burns, J. C. Crittenden, D. W. Hand, V. H. Selzer, L. L. Sutter, and S. R. Salman, "Effect of Inorganic Ions in Heterogeneous Photocatalysis of TCE," Journal of Environmental Engineering, vol. 125, no. 1, pp. 77-85, 1999.

[18] S. Li, Z. Ma, J. Zhang, Y. Wu, and Y. Gong, "A comparative study of photocatalytic degradation of phenol of $\mathrm{TiO} 2$ and $\mathrm{ZnO}$ in the presence of manganese dioxides," Catalysis Today, vol. 139, pp. 109-112, 2008.

[19] X. Van Doorslaer, P. M. Heynderickx, K. Demeestere, K. Debevere, H. Van Langenhove, and J. Dewulf, "TiO2 mediated heterogeneous photocatalytic degradation of moxifloxacin: Operational variables and scavenger study," Applied Catalysis B: Environmental, vol. 111112, pp. 150-156, 2012.

[20] N. Kashif and F. Ouyang, "Parameters effect on heterogeneous photocatalysed degradation of phenol in aqueous dispersion of TiO2," Journal of Environmental Sciences, vol. 21, no. 4, pp. 527-533, 2009.

[21] D. D. Dionysiou, M. T. Suidan, E. Bekou, I. Baudin, and J.-M. La^, "Effect of ionic strength and hydrogen peroxide on the photocatalytic degradation of 4-chlorobenzoic acid in water," vol. 26, pp. 153-171, 2000.

[22] A. Aguedach, S. Brosillon, J. Morvan, and E. K. Lhadi, "Influence of ionic strength in the adsorption and during photocatalysis of reactive black 5 azo dye on $\mathrm{TiO} 2$ coated on non woven paper with $\mathrm{SiO} 2$ as a binder.," Journal of hazardous materials, vol. 150, pp. 250-6, 2008.

[23] A. Lair, C. Ferronato, J.-M. Chovelon, and J.-M. Herrmann, "Naphthalene degradation in water by heterogeneous photocatalysis: An investigation of the influence of inorganic anions," Journal of Photochemistry and Photobiology A: Chemistry, vol. 193, no. 2-3, pp. 193-203, 2008.

[24] S. Y. Yang, Y. X. Chen, L. P. Lou, and X. N. Wu, "Involvement of chloride anion in photocatalytic process," Journal Of Environmental Sciences (China), vol. 17, no. 5, pp. 761765, 2005.

[25] C. Kormann, D. W. Bahnemann, and M. R. Hoffmann, "Photolysis of chloroform and other organic molecules in aqueous titanium dioxide suspensions," Environmental Science \& Technology, vol. 25, no. 3, pp. 494-500, 1991.

[26] J. E. Grebel, J. J. Pignatello, and W. A. Mitch, "Effect of halide ions and carbonates on organic contaminant degradation by hydroxyl radical-based advanced oxidation processes in saline waters," Environmental Science \& Technology, vol. 44, no. 17, pp. 6822-8, 2010.

[27] A. J. Machulek, J. E. F. Moraes, C. Vautier-Giongo, C. A. Silverio, L. C. Friedrich, C. a. O. Nascimento, M. C. Gonzalez, and F. H. Quina, "Abatement of the inhibitory effect of chloride anions on the photo-Fenton process," Environmental Science \& Technology, vol. 41, no. 24, pp. 8459-63, 2007.

[28] Farhataziz and A. B. Ross, "Selected specific rates of reactions of transients from water in aqueous solution. III. Hydroxyl radical and perhydroxyl radical and their radical ions," in National Standard Reference Data Series, N. B. o. Standards, Ed., ed, 1977. 
[29] J. Rabani, K. Yamashita, K. Ushida, J. Stark, and A. Kira, "Fundamental Reactions in Illuminated Titanium Dioxide Nanocrystallite Layers Studied by Pulsed Laser," The Journal of Physical Chemistry B, vol. 102, no. 10, pp. 1689-1695, 1998.

[30] Y. Chen, S. Yang, K. Wang, and L. Lou, "Role of primary active species and TiO2 surface characteristic in UV-illuminated photodegradation of Acid Orange 7," Journal of Photochemistry and Photobiology A: Chemistry, vol. 172, no. 1, pp. 47-54, 2005.

[31] R. Palominos, J. Freer, M. A. Mondaca, and H. D. Mansilla, "Evidence for hole participation during the photocatalytic oxidation of the antibiotic flumequine," Journal of Photochemistry and Photobiology A: Chemistry, vol. 193, no. 2-3, pp. 139-145, 2008.

[32] P. A. Connor and A. J. Mcquillan, "Phosphate Adsorption onto TiO2 from Aqueous Solutions An in Situ Internal Reflection Infrared Spectroscopic Study," Langmuir, vol. 15, no. 8, pp. 2916-2921, 1999.

[33] D. Zhao, C. Chen, Y. Wang, H. Ji, W. Ma, L. Zang, and J. Zhao, "Surface Modification of TiO2 by Phosphate: Effect on Photocatalytic Activity and Mechanism Implication," The Journal of Physical Chemistry C, vol. 112, no. 15, pp. 5993-6001, 2008.

[34] J. Kim and W. Choi, "TiO2 modified with both phosphate and platinum and its photocatalytic activities," Applied Catalysis B: Environmental, vol. 106, no. 1-2, pp. 39-45, 2011.

[35] H. Sheng, Q. Li, W. Ma, H. Ji, C. Chen, and J. Zhao, "Photocatalytic degradation of organic pollutants on surface anionized TiO2: Common effect of anions for high hole-availability by water," Applied Catalysis B: Environmental, vol. 138-139, pp. 212-218, 2013.

[36] R. E. Huie, P. Neta, and C. K. Division, "Rate constants for some oxidations of S(IV) by radicals in aqueous solutions," Atmospheric Environment (1967), vol. 21, no. 8, pp. 17431747, 1987.

[37] C. Hu, J. C. Yu, Z. Hao, and P. K. K. Wong, "Effects of acidity and inorganic ions on the photocatalytic degradation of different azo dyes," Applied Catalysis B: Environmental, vol. 46, no. 1, pp. 35-47, 2003.

[38] S. Chen and G. Cao, "Study on the photocatalytic reduction of dichromate and photocatalytic oxidation of dichlorvos," Chemosphere, vol. 60, no. 9, pp. 1308-15, 2005.

[39] Z. Hua, M. P. Zhang, Z. F. Xia, and G. K. C. Low, "Titanium-Dioxide Mediated Photocatalytic Degradation of Monocrotophos," Water Research, vol. 29, no. 12, pp. 26812688, 1995.

[40] P. Mazellier, E. Leroy, J. De Laat, and B. Legube, "Transformation of carbendazim induced by the H2O2/UV system in the presence of hydrogenocarbonate ions : involvement of the carbonate radical," New Journal of Chemistry, vol. 26, no. 12, pp. 1784-1790, 2002.

[41] R. A. Larson and R. G. Zepp, "Reactivity of the carbonate radical with aniline derivatives," Environmental Toxicology and Chemistry, vol. 7, no. 4, pp. 265-274, 1988.

[42] A. Kumar and N. Mathur, "Photocatalytic degradation of aniline at the interface of TiO2 suspensions containing carbonate ions," Journal of colloid and interface science, vol. 300, no. 1, pp. 244-52, 2006.

[43] J. Q. Chen, Z. J. Hu, D. Wang, C. J. Gao, and R. Ji, "Photocatalytic mineralization of dimethoate in aqueous solutions using TiO2: Parameters and by-products analysis," Desalination, vol. 258, no. 1-3, pp. 28-33, 2010.

[44] A. N. Acevedo, E. A. Carpio, J. RodríGuez, and M. A. Manzano, "Disinfection of Natural Water by Solar Photocatalysis Using Immobilized TiO2 Devices: Efficiency in Eliminating Indicator Bacteria and Operating Life of the System," Journal of Solar Energy Engineering, vol. 134, no. 1, pp. 011008-011008, 2012.

[45] H. Y. Chen, O. Zahraa, and M. Bouchy, "Inhibition of the adsorption and photocatalytic degradation of an organic contaminant in an aqueous suspension of TiO 2 by inorganic ions," Journal of Photochemistry and ..., vol. 108, pp. 37-44, 1997.

[46] J. L. Lucas Vaz, A. Boussaoud, Y. Ait Ichou, and M. Petit-Ramel, "Photominéralisation de l'uracile et des 5-halogeno-uraciles sur le dioxyde de titane. Effet du $\mathrm{pH}$ et de quelques anions sur la photodégradation de l'uracile," Analusis, vol. 26, no. 2, pp. 83-87, 1998.

[47] M. Abdullah, G. K. C. Low, and R. W. Matthews, "Effects of common inorganic anions on rates of photocatalytic oxidation of organic carbon over illuminated titanium dioxide," Journal of Physical Chemistry, vol. 94, no. 17, pp. 6820-6825, 1990. 
[48] S. Qourzal, M. Tamimi, A. Assabbane, and Y. Ait-Ichou, "Influence de certains ions inorganiques, de l'éthanol et du peroxyde d'hydrogène sur la photominéralisation du $\beta$-naphtol en présence de TiO2," Comptes Rendus Chimie, vol. 10, no. 12, pp. 1187-1194, 2007.

[49] R. G. Zepp, J. Hoigne, and H. Bader, "Nitrate-induced photooxidation of trace organic chemicals in water," Environmental science \& ..., vol. 21, no. 5, pp. 443-450, 1987.

[50] M. Bekbölet, Z. Boyacioglu, and B. Özkaraova, "The influence of solution matrix on the photocatalytic removal of color from natural waters," Water Science and Technology, vol. 38, pp. 155-162, 1998.

[51] Y. Du, S. Goldstein, and J. Rabani, "The catalytic effects of copper ions on photo-oxidation in TiO2 suspensions: The role of superoxide radicals," Journal of Photochemistry and Photobiology A: Chemistry, vol. 225, no. 1, pp. 1-7, 2011.

[52] V. Brezová, A. Blažková, E. Borošová, M. Čeppan, and R. Fiala, "The influence of dissolved metal ions on the photocatalytic degradation of phenol in aqueous $\mathrm{TiO} 2$ suspensions," Journal of Molecular Catalysis A: Chemical, vol. 98, no. 2, pp. 109-116, 1995.

[53] G. Laera, B. Jin, H. Zhu, and A. Lopez, "Photocatalytic activity of TiO2 nanofibers in simulated and real municipal effluents," Catalysis Today, vol. 161, pp. 147-152, 2011.

[54] X. Z. Li, C. M. Fan, and Y. P. Sun, "Enhancement of photocatalytic oxidation of humic acid in TiO2 suspensions by increasing cation strength," Chemosphere, vol. 48, no. 4, pp. 453-60, 2002.

[55] P. Vanýsek, "Electrochemical Series," W. M. Haynes, Ed., 94th Editi ed: CRC Press, 2013, pp. 5-80-5-89.

[56] K. Rajeshwar, C. R. Chenthamarakshan, Y. Ming, and W. Sun, "Cathodic photoprocesses on titania films and in aqueous suspensions," Journal of Electroanalytical Chemistry, vol. 538539, pp. 173-182, 2002.

[57] A. Lozano, J. Garcia, X. Dormènech, and J. Casado, "Heterogeneous photocatalytic oxidation of manganese(II) over TiO2," Journal of Photochemistry and Photobiology A: Chemistry, vol. 69, no. 2, pp. 237-240, 1992.

[58] Y. Ming, C. R. Chenthamarakshan, and K. Rajeshwar, "Radical-mediated photoreduction of manganese(II) species in UV-irradiated titania suspensions," Journal of Photochemistry and Photobiology A: Chemistry, vol. 147, no. 3, pp. 199-204, 2002.

[59] M. R. Prairie, L. R. Evans, B. M. Stange, and S. L. Martinez, "An investigation of titanium dioxide photocatalysis for the treatment of water contaminated with metals and organic chemicals," Environmental Science \& Technology, vol. 27, no. 9, pp. 1776-1782, 1993.

[60] S. Li, Z. Ma, J. Zhang, and J. Liu, "Photocatalytic activity of TiO2 and ZnO in the presence of manganese dioxides," Catalysis Communications, vol. 9, no. 6, pp. 1482-1486, 2008.

[61] M. Addamo, M. Bellardita, D. Carriazo, A. Di Paola, S. Milioto, L. Palmisano, and V. Rives, "Inorganic gels as precursors of $\mathrm{TiO} 2$ photocatalysts prepared by low temperature microwave or thermal treatment," Applied Catalysis B: Environmental, vol. 84, no. 3-4, pp. 742-748, 2008.

[62] N. N. Rao and V. Chaturvedi, "Photoactivity of TiO2-Coated Pebbles," Industrial \& Engineering Chemistry Research, vol. 46, no. 13, pp. 4406-4414, 2007.

[63] E. C. Butler and A. P. Davis, "Photocatalytic oxidation in aqueous titanium dioxide suspensions: the influence of dissolved transition metals," Journal of Photochemistry and Photobiology A: Chemistry, vol. 70, no. 3, pp. 273-283, 1993.

[64] J. N. Chen, Y. C. Chan, and M. C. Lu, "Photocatalytic oxidation of chlorophenols in the presence of manganese ions," Water Science and Technology, vol. 39, no. 10-11, pp. 225230, 1999.

[65] S. Tuprakay and W. Liengcharernsit, "Lifetime and regeneration of immobilized titania for photocatalytic removal of aqueous hexavalent chromium," Journal of hazardous materials, vol. 124, no. 1-3, pp. 53-8, 2005.

[66] N. Wang, Y. Xu, L. Zhu, X. Shen, and H. Tang, "Reconsideration to the deactivation of TiO2 catalyst during simultaneous photocatalytic reduction of $\operatorname{Cr}(\mathrm{VI})$ and oxidation of salicylic acid," Journal of Photochemistry and Photobiology A: Chemistry, vol. 201, no. 2-3, pp. 121127, 2009. 
[67] M. S. Siboni, M.-T. Samadi, Y. Jae-Kyu, and L. Seung-Mok, "Photocatalytic removal of CPR(VI) and Ni(II) by UV/TiO2: kinetic study," Desalination \& Water Treatment, vol. 40, no. 1-3, pp. 77-83, 2012.

[68] J.-K. Yang and S.-M. Lee, "Removal of $\mathrm{Cr}(\mathrm{VI})$ and humic acid by using $\mathrm{TiO} 2$ photocatalysis," Chemosphere, vol. 63, no. 10, pp. 1677-84, 2006.

[69] C. He, Y. Xiong, and X. Zhu, "Strategies for regeneration of copper (0)-deposited TiO2 photocatalytic film," Journal of Environmental Science and Health, Part A: Toxic/Hazardous Substances and Environmental Engineering, vol. 37, no. 8, pp. 1545-1562, 2002.

[70] S. W. Zou, C. W. How, and J. P. Chen, "Photocatalytic Treatment of Wastewater Contaminated with Organic Waste and Copper Ions from the Semiconductor Industry," Industrial \& Engineering Chemistry Research, vol. 46, no. 20, pp. 6566-6571, 2007.

[71] S. Yamazaki, N. Takemura, Y. Yoshinaga, and A. Yoshida, "Transmittance change of the TiO2 thin film by photoreductive deposition of $\mathrm{Cu}(\mathrm{II}), "$ Journal of Photochemistry and Photobiology A: Chemistry, vol. 161, no. 1, pp. 57-60, 2003.

[72] N. S. Foster, R. D. Noble, and C. A. Koval, "Reversible photoreductive deposition and oxidative dissolution of copper ions in titanium dioxide aqueous suspensions," Environmental Science \& Technology, vol. 27, no. 2, pp. 350-356, 1993.

[73] S. W. Lam, M. Hermawan, H. M. Coleman, K. Fisher, and R. Amal, "The role of copper(II) ions in the photocatalytic oxidation of 1,4-dioxane," Journal of Molecular Catalysis A: Chemical, vol. 278, no. 1-2, pp. 152-159, 2007.

[74] S. Lam, K. Chiang, T. Lim, R. Amal, and G. Low, "Effect of charge trapping species of cupric ions on the photocatalytic oxidation of resorcinol," Applied Catalysis B: Environmental, vol. 55, no. 2, pp. 123-132, 2005.

[75] D. Klauson and S. Preis, "The Influence of Iron Ions on the Aqueous Photocatalytic Oxidation of Deicing Agents," INTERNATIONAL JOURNAL OF PHOTOENERGY, vol. 2007, pp. 1-7, 2007.

[76] W. Baran, A. Makowski, and W. Wardas, "The influence of FeCl3 on the photocatalytic degradation of dissolved azo dyes in aqueous TiO2 suspensions.," Chemosphere, vol. 53, pp. 87-95, 2003.

[77] R. J. Knight and R. N. Sylva, "Spectrophotometric investigation of iron(III) hydrolysis in light and heavy water at $25^{\circ} \mathrm{C}$," Journal of Inorganic and Nuclear Chemistry, vol. 37, no. 3, pp. 779-783, 1975.

[78] T. Arakaki and B. C. Faust, "Sources, sinks, and mechanisms of hydroxyl radical $(\bullet \mathrm{OH})$ photoproduction and consumption in authentic acidic continental cloud waters from Whiteface Mountain, New York: The role of the Fe(r) (r = II, III) photochemical cycle," Journal of Geophysical Research, vol. 103, no. D3, pp. 3487-3504, 1998.

[79] B. C. Faust and J. Hoigné, "Photolysis of Fe (III)-hydroxy complexes as sources of OH radicals in clouds, fog and rain," Atmospheric Environment. Part A. General Topics, vol. 24, no. 1, pp. 79-89, 1990.

[80] F. Forouzan, T. C. Richards, and A. J. Bard, "Photoinduced Reaction at TiO2 Particles. Photodeposition from NiII Solutions with Oxalate," The Journal of Physical Chemistry, vol. 100, no. 46, pp. 18123-18127, 1996.

[81] W. Y. Lin and K. Rajeshwar, "Photocatalytic Removal of Nickel from Aqueous Solutions Using Ultraviolet-Irradiated TiO2," Journal of the Electrochemical Society, vol. 144, no. 8, pp. 2751-2756, 1997.

[82] M. Carrier, N. Perol, J.-M. Herrmann, C. Bordes, S. Horikoshi, J. O. Paisse, R. Baudot, and C. Guillard, "Kinetics and reactional pathway of Imazapyr photocatalytic degradation Influence of $\mathrm{pH}$ and metallic ions," Applied Catalysis B: Environmental, vol. 65, no. 1-2, pp. 11-20, 2006.

[83] L. Murruni, F. Conde, G. Leyva, and M. I. Litter, "Photocatalytic reduction of Pb(II) over TiO2: New insights on the effect of different electron donors," Applied Catalysis B: Environmental, vol. 84, no. 3-4, pp. 563-569, 2008.

[84] C. R. Chenthamarakshan, H. Yang, C. R. Savage, and K. Rajeshwar, "Photocatalytic Reactions of Divalent Lead Ions in Uv-Irradiated Titania Suspensions," Research on Chemical Intermediates, vol. 25, no. 9, pp. 861-876, 1999. 
[85] L. Murruni, G. Leyva, and M. I. Litter, "Photocatalytic removal of Pb(II) over TiO2 and PtTiO2 powders," Catalysis Today, vol. 129, no. 1-2, pp. 127-135, 2007.

[86] Z. P. Yang and C. J. Zhang, "Kinetics of photocatalytic reduction of Pb(II) on nanocrystalline TiO2 coatings: A quartz crystal microbalance study," Thin Solid Films, vol. 518, no. 21, pp. 6006-6009, 2010.

[87] S. Chen and Y. Liu, "Study on the photocatalytic degradation of glyphosate by $\operatorname{TiO}(2)$ photocatalyst.," Chemosphere, vol. 67, pp. 1010-7, 2007.

[88] M. C. Lu, J. N. Chen, and H. D. Lin, "The influence of metal ions on the photocatalytic oxidation of 2-chlorophenol in aqueous titanium dioxide suspensions," Journal of Environmental Science and Health, Part B, vol. 34, no. 1, pp. 17-32, 1999.

[89] S. Somasundaram, Y. Ming, C. R. Chenthamarakshan, Z. A. Schelly, and K. Rajeshwar, "Free Radical-Mediated Heterogeneous Photocatalytic Reduction of Metal Ions in UVIrradiated Titanium Dioxide Suspensions," no. Ii, pp. 4784-4788, 2004.

[90] B. Lopez-Alvarez, R. A. Torres-Palma, and G. Peñuela, "Solar photocatalitycal treatment of carbofuran at lab and pilot scale: effect of classical parameters, evaluation of the toxicity and analysis of organic by-products," Journal of Hazardous Materials, vol. 191, no. 1-3, pp. 196203, 2011.

[91] C. Lin and K. S. Lin, "Photocatalytic oxidation of toxic organohalides with TiO2/UV: the effects of humic substances and organic mixtures," Chemosphere, vol. 66, no. 10, pp. 1872-7, 2007.

[92] S. Goldstein, D. Behar, and J. Rabani, "Mechanism of Visible Light Photocatalytic Oxidation of Methanol in Aerated Aqueous Suspensions of Carbon-Doped TiO2," The Journal of Physical Chemistry C, vol. 112, no. 39, pp. 15134-15139, 2008.

[93] R. Hazime, C. Ferronato, L. Fine, A. Salvador, F. Jaber, and J. M. Chovelon, "Photocatalytic degradation of imazalil in an aqueous suspension of TiO2 and influence of alcohols on the degradation," Applied Catalysis B: Environmental, vol. 126, pp. 90-99, 2012.

[94] G. Epling and C. Lin, "Investigation of retardation effects on the titanium dioxide photodegradation system," Chemosphere, vol. 46, no. 6, pp. 937-44, 2002.

[95] D. V. Sojić, V. B. Anderluh, D. Z. Orcić, and B. F. Abramović, "Photodegradation of clopyralid in TiO2 suspensions: identification of intermediates and reaction pathways," Journal of Hazardous Materials, vol. 168, no. 1, pp. 94-101, 2009.

[96] S. H. Kim and H. K. Shon, "Adsorption Characterization for Multicomponent Organic Matters by Titanium Oxide (TiO2 ) in Wastewater," Separation Science and Technology, vol. 42, no. 8, pp. 1775-1792, 2007.

[97] K. Yang, D. Lin, and B. Xing, "Interactions of Humic Acid with Nanosized Inorganic Oxides," Langmuir, vol. 25, no. 6, pp. 3571-3576, 2009.

[98] J. Wiszniowski, D. Robert, J. Surmacz-Gorska, K. Miksch, and J.-V. Weber, "Photocatalytic decomposition of humic acids on TiO2: Part I: Discussion of adsorption and mechanism," Journal of Photochemistry and Photobiology A: Chemistry, vol. 152, no. 1-3, pp. 267-273, 2002.

[99] R. Enriquez and P. Pichat, "Interactions of Humic Acid, Quinoline, and TiO2 in Water in Relation to Quinoline Photocatalytic Removal," Langmuir, vol. 17, no. 20, pp. 6132-6137, 2001.

[100] M. Bekbölet and I. Balcioglu, "Photocatalytic degradation kinetics of humic acid in aqueous TiO2 dispersions: The influence of hydrogen peroxide and bicarbonate ion," Water Science and Technology, vol. 34, no. 9, pp. 73-80, 1996.

[101] S. Liu, M. Lim, R. Fabris, C. Chow, K. Chiang, M. Drikas, and R. Amal, "Removal of humic acid using $\mathrm{TiO} 2$ photocatalytic process--fractionation and molecular weight characterisation studies," Chemosphere, vol. 72, no. 2, pp. 263-71, 2008.

[102] M. Mori, T. Sugita, A. Mase, T. Funatogawa, M. Kikuchi, K. Aizawa, S. Kato, Y. Saito, T. Ito, and H. Itabashi, "Photodecomposition of humic acid and natural organic matter in swamp water using a $\mathrm{TiO}(2)$-coated ceramic foam filter: potential for the formation of disinfection byproducts," Chemosphere, vol. 90, no. 4, pp. 1359-65, 2013. 
[103] C. X. Zhang and Y. X. Wang, "Effects of dissolved organic matter in landfill leachate on photodegradation of environmental endocrine disruptors," International Journal of Environment and ..., vol. 45, no. 1-3, pp. 69-80, 2011.

[104] T. E. Doll and F. H. Frimmel, "Photocatalytic degradation of carbamazepine, clofibric acid and iomeprol with P25 and Hombikat UV100 in the presence of natural organic matter (NOM) and other organic water constituents," Water research, vol. 39, no. 2-3, pp. 403-11, 2005.

[105] J. Krýsa, P. Novotná, Š. Kment, and A. Mills, "Effect of glass substrate and deposition technique on the properties of sol gel TiO2 thin films," Journal of Photochemistry and Photobiology A: Chemistry, vol. 222, no. 1, pp. 81-86, 2011.

[106] L. Lopez, W. A. Daoud, D. Dutta, B. C. Panther, and T. W. Turney, "Effect of substrate on surface morphology and photocatalysis of large-scale TiO2 films," Applied Surface Science, vol. 265, pp. 162-168, 2013.

[107] H. J. Nam, T. Amemiya, M. Murabayashi, and K. Itoh, "Photocatalytic Activity of Sol-Gel $\mathrm{TiO} 2$ Thin Films on Various Kinds of Glass Substrates The Effects of $\mathrm{Na}+$ and Primary Particle Size," The Journal of Physical Chemistry B, vol. 108, no. 24, pp. 8254-8259, 2004.

[108] Š. Kment, I. Gregora, H. Kmentová, P. Novotná, Z. Hubička, J. Krýsa, P. Sajdl, A. Dejneka, M. Brunclíková, L. Jastrabík, and M. Hrabovský, "Raman spectroscopy of dip-coated and spin-coated sol-gel TiO2 thin films on different types of glass substrate," Journal of Sol-Gel Science and Technology, vol. 63, no. 3, pp. 294-306, 2012.

[109] E. Aubry, J. Lambert, V. Demange, and A. Billard, "Effect of Na diffusion from glass substrate on the microstructural and photocatalytic properties of post-annealed $\mathrm{TiO} 2$ films synthesised by reactive sputtering," Surface and Coatings Technology, vol. 206, no. 23, pp. 4999-5005, 2012.

[110] Y. Chen and D. D. Dionysiou, "Correlation of structural properties and film thickness to photocatalytic activity of thick TiO2 films coated on stainless steel," Applied Catalysis B: Environmental, vol. 69, no. 1-2, pp. 24-33, 2006.

[111] G. Balasubramanian, D. D. Dionysiou, M. T. Suidan, V. Subramanian, I. Baudin, and J. M. Laîné, "Titania powder modified sol-gel process for photocatalytic applications," Journal of Materials Science, vol. 38, no. 4, pp. 823-831, 2003.

[112] C. Guillard, B. Beaugiraud, C. Dutriez, J.-M. Herrmann, H. Jaffrezic, N. Jaffrezic-Renault, and M. Lacroix, "Physicochemical properties and photocatalytic activities of TiO 2-films prepared by sol-gel methods," Applied Catalysis B: ..., vol. 39, no. 4, pp. 331-342, 2002.

[113] M. Vargová, G. Plesch, U. F. Vogt, M. Zahoran, M. Gorbár, and K. Jesenák, "TiO2 thick films supported on reticulated macroporous $\mathrm{Al} 2 \mathrm{O} 3$ foams and their photoactivity in phenol mineralization," Applied Surface Science, vol. 257, no. 10, pp. 4678-4684, 2011.

[114] S.-Z. Chen, P.-Y. Zhang, W.-P. Zhu, L. Chen, and S.-M. Xu, "Deactivation of TiO2 photocatalytic films loaded on aluminium: XPS and AFM analyses," Applied Surface Science, vol. 252, no. 20, pp. 7532-7538, 2006.

[115] M. A. Fox and M. T. Dulay, "Heterogeneous photocatalysis," Chemical reviews, 1993.

[116] Y. Chen and D. D. Dionysiou, "TiO2 photocatalytic films on stainless steel: The role of Degussa P-25 in modified sol-gel methods," Applied Catalysis B: Environmental, vol. 62, no. 3-4, pp. 255-264, 2006.

[117] P. Evans and D. W. Sheel, "Photoactive and antibacterial TiO2 thin films on stainless steel," Surface and Coatings Technology, vol. 201, no. 22-23, pp. 9319-9324, 2007.

[118] N. N. Rao and V. Chaturvedi, "Photoactivity of TiO2 Coated Pebbles," Industrial \& Engineering Chemistry Research, vol. 46, pp. 4406-4414, 2007.

[119] T.-H. Xie and J. Lin, "Origin of Photocatalytic Deactivation of TiO2 Film Coated on Ceramic Substrate," The Journal of Physical Chemistry C, vol. 111, no. 27, pp. 9968-9974, 2007.

[120] K. Hund-Rinke and M. Simon, "Ecotoxic effect of photocatalytic active nanoparticles (TiO2) on algae and daphnids," Environmental science and pollution research international, vol. 13, no. 4, pp. 225-32, 2006.

[121] B. J. Cardinale, R. Bier, and C. Kwan, "Effects of TiO2 nanoparticles on the growth and metabolism of three species of freshwater algae," Journal of Nanoparticle Research, vol. 14, no. 8, pp. 913-913, 2012. 
[122] D. M. Metzler, M. Li, A. Erdem, and C. P. Huang, "Responses of algae to photocatalytic nano-TiO2 particles with an emphasis on the effect of particle size," Chemical Engineering Journal, vol. 170, no. 2-3, pp. 538-546, 2011.

[123] K. V. S. Rao, M. Subrahmanyam, and P. Boule, "Immobilized TiO2 photocatalyst during long-term use: decrease of its activity," Applied Catalysis B: Environmental, vol. 49, no. 4, pp. 239-249, 2004.

[124] N. J. Peill and M. R. Hoffmann, "Chemical and Physical Characterization of a TiO2-Coated Fiber Optic Cable Reactor," Environmental Science \& Technology, vol. 30, no. 9, pp. 28062812, 1996.

[125] U. Černigoj, U. L. Štangar, and P. Trebše, "Evaluation of a novel Carberry type photoreactor for the degradation of organic pollutants in water," Journal of Photochemistry and Photobiology A: Chemistry, vol. 188, no. 2-3, pp. 169-176, 2007.

[126] M. Bideau, B. Claudel, C. Dubien, L. Faure, and H. Kazouan, "On the "immobilization" of titanium dioxide in the photocatalytic oxidation of spent waters," Journal of Photochemistry and Photobiology A: Chemistry, vol. 91, no. 2, pp. 137-144, 1995.

[127] S. Souzanchi, F. Vahabzadeh, S. Fazel, and S. N. Hosseini, "Performance of an Annular Sieve-Plate Column photoreactor using immobilized $\mathrm{TiO} 2$ on stainless steel support for phenol degradation," Chemical Engineering Journal, vol. 223, no. 0, pp. 268-276, 2013.

[128] A. Fernhndez, G. Lassaletta, V. M. Jimknez, A. Justo, A. Fernández, V. M. Jiménez, A. R. González-Elipe, J. M. Herrmann, H. Tahiri, and Y. Ait-Ichou, "Preparation and characterization of $\mathrm{TiO} 2$ photocatalysts supported on various rigid supports (glass, quartz and stainless steel). Comparative studies of photocatalytic activity in water purification," Applied Catalysis B: Environmental, vol. 7, no. 1-2, pp. 49-63, 1995.

[129] M. Karches, M. Morstein, P. Rudolf Von Rohr, R. L. Pozzo, J. L. Giombi, and M. A. Baltanás, "Plasma-CVD-coated glass beads as photocatalyst for water decontamination," Catalysis Today, vol. 72, no. 3-4, pp. 267-279, 2002.

[130] A. Mills, A. Lepre, N. Elliott, S. Bhopal, I. P. Parkin, and S. A. O’neill, "Characterisation of the photocatalyst Pilkington Activ ${ }^{\mathrm{TM}}$ : a reference film photocatalyst?," Journal of Photochemistry and Photobiology A: Chemistry, vol. 160, no. 3, pp. 213-224, 2003.

[131] J. Olabarrieta, S. Zorita, I. Peña, N. Rioja, O. Monzón, P. Benguria, and L. Scifo, "Aging of photocatalytic coatings under a water flow: Long run performance and $\mathrm{TiO} 2$ nanoparticles release," Applied Catalysis B: Environmental, vol. 123-124, pp. 182-192, 2012.

[132] M. A. Kiser, P. Westerhoff, T. Benn, Y. Wang, J. Pérez-Rivera, and K. Hristovski, "Titanium nanomaterial removal and release from wastewater treatment plants," Environmental science \& technology, vol. 43, no. 17, pp. 6757-63, 2009.

[133] P. Westerhoff, G. Song, K. Hristovski, and M. A. Kiser, "Occurrence and removal of titanium at full scale wastewater treatment plants: implications for TiO2 nanomaterials," Journal of environmental monitoring : JEM, vol. 13, no. 5, pp. 1195-203, 2011.

[134] R. Kaegi, A. Ulrich, B. Sinnet, R. Vonbank, A. Wichser, S. Zuleeg, H. Simmler, S. Brunner, H. Vonmont, M. Burkhardt, and M. Boller, "Synthetic TiO2 nanoparticle emission from exterior facades into the aquatic environment," Environmental pollution (Barking, Essex : 1987), vol. 156, no. 2, pp. 233-9, 2008.

[135] L. Zhang, P. Zhang, and S. Chen, "Influence of Pretreatment of Titanium Substrate on LongTerm Stability of TiO2 Film," Chinese Journal of Catalysis, vol. 28, no. 4, pp. 299-306, 2007.

[136] M. A. Behnajady, S. Amirmohammadi-Sorkhabi, N. Modirshahla, and M. Shokri, "Investigation of the efficiency of a tubular continuous-flow photoreactor with supported titanium dioxide nanoparticles in the removal of 4-nitrophenol: operational parameters, kinetics analysis and mineralization studies," Water Science \& Technology, vol. 64, no. 1, pp. 56-56, 2011.

[137] S. Gautam, S. P. Kamble, S. B. Sawant, and V. G. Pangarkar, "Photocatalytic degradation of 4-nitroaniline using solar and artificial UV radiation," Chemical Engineering Journal, vol. 110, no. 1-3, pp. 129-137, 2005.

[138] L. Mi, P. Xu, H. Shen, and P.-N. Wang, "Recovery of visible-light photocatalytic efficiency of N-doped TiO2 nanoparticulate films," Journal of Photochemistry and Photobiology A: Chemistry, vol. 193, no. 2-3, pp. 222-227, 2008. 
[139] S.-J. Hwang, C. Petucci, and D. Raftery, "In Situ Solid-State NMR Studies of Trichloroethylene Photocatalysis: Formation and Characterization of Surface-Bound Intermediates," Journal of the American Chemical Society, vol. 120, no. 18, pp. 4388-4397, 1998.

[140] N. Miranda-García, S. Suárez, B. Sánchez, J. M. Coronado, S. Malato, and M. I. Maldonado, "Photocatalytic degradation of emerging contaminants in municipal wastewater treatment plant effluents using immobilized TiO2 in a solar pilot plant," Applied Catalysis B: Environmental, vol. 103, no. 3-4, pp. 294-301, 2011.

[141] W. H. Glaze, J. F. Kenneke, and J. L. Ferry, "Chlorinated byproducts from the titanium oxidemediated photodegradation of trichloroethylene and tetrachloroethylene in water," Environmental Science \& Technology, vol. 27, no. 1, pp. 177-184, 1993.

[142] J. J. Molnar, J. R. Agbaba, B. D. Dalmacija, M. T. Klašnja, M. B. Dalmacija, and M. M. Kragulj, "A comparative study of the effects of ozonation and TiO2-catalyzed ozonation on the selected chlorine disinfection by-product precursor content and structure," The Science of the total environment, vol. 425, pp. 169-75, 2012.

[143] F. C. Kent, K. R. Montreuil, R. M. Brookman, R. Sanderson, J. R. Dahn, and G. A. Gagnon, "Photocatalytic oxidation of DBP precursors using UV with suspended and fixed TiO2," Water Research, vol. 45, no. 18, pp. 6173-80, 2011.

[144] L. A. Tercero Espinoza and F. H. Frimmel, "Formation of brominated products in irradiated titanium dioxide suspensions containing bromide and dissolved organic carbon," Water Research, vol. 42, no. 6-7, pp. 1778-84, 2008.

[145] K. K. Philippe, C. Hans, J. Macadam, B. Jefferson, J. Hart, and S. A. Parsons, "Photocatalytic oxidation of natural organic matter surrogates and the impact on trihalomethane formation potential," Chemosphere, vol. 81, no. 11, pp. 1509-16, 2010.

[146] F. Denny, P. Mccaffrey, J. Scott, G. D. Peng, and R. Amal, "A mesoporous SiO2 intermediate layer for improving light propagation in a bundled tube photoreactor," Chemical Engineering Science, vol. 66, no. 16, pp. 3641-3647, 2011.

[147] S. Xu, J. Ng, Y. Wang, A. J. Du, and D. D. Sun, "Simultaneous copper ion removal and hydrogen production from water over a TiO2 nanotube photocatalyst," Water Science and Technology, vol. 65, no. 3, pp. 533-538, 2012.

[148] M. M. Mohamed, I. Othman, and R. M. Mohamed, "Synthesis and characterization of $\mathrm{MnOx} / \mathrm{TiO} 2$ nanoparticles for photocatalytic oxidation of indigo carmine dye," Journal of Photochemistry and Photobiology A: Chemistry, vol. 191, pp. 153-161, 2007.

[149] V. G. Gandhi, M. K. Mishra, and P. A. Joshi, "A study on deactivation and regeneration of titanium dioxide during photocatalytic degradation of phthalic acid," Journal of Industrial and Engineering Chemistry, vol. 18, no. 6, pp. 1902-1907, 2012.

[150] A. Özkan, M. H. Özkan, R. Gürkan, M. Akçay, and M. Sökmen, "Photocatalytic degradation of a textile azo dye, Sirius Gelb GC on TiO2 or Ag-TiO2 particles in the absence and presence of UV irradiation: the effects of some inorganic anions on the photocatalysis," Journal of Photochemistry and Photobiology A: Chemistry, vol. 163, no. 1-2, pp. 29-35, 2004.

[151] M. I. Franch, J. Peral, X. Domenech, and J. A. Ayllon, "Aluminium(III) adsorption: a soft and simple method to prevent TiO2 deactivation during salicylic acid photodegradation," Chemical communications, no. 14, pp. 1851-3, 2005.

[152] G. V. Buxton, C. L. Greenstock, W. P. Helman, and A. B. Ross, "Critical Review of rate constants for reactions of hydrated electrons, hydrogen atoms and hydroxyl radicals $\cdot \mathrm{OH} / \mathrm{O}^{-}$ in Aqueous Solution," Journal of Physical and Chemical Reference Data, vol. 17, no. 2, pp. 513-886, 1988.

[153] J. Kochany and E. Lipczynska-Kochany, "Application of the EPR spin-trapping technique for the investigation of the reactions of carbonate, bicarbonate, and phosphate anions with hydroxyl radicals generated by the photolysis of H2O2," Chemosphere, vol. 25, no. 12, pp. 1769-1782, 1992.

[154] Y. Tang, R. P. Thorn, R. L. Mauldin Iii, and P. H. Wine, "Kinetics and spectroscopy of the SO4- radical in aqueous solution," Journal of Photochemistry and Photobiology A: Chemistry, vol. 44, no. 3, pp. 243-258, 1988. 
[155] K. Wang, J. Zhang, L. Lou, S. Yang, and Y. Chen, "UV or visible light induced photodegradation of $\mathrm{AO} 7$ on $\mathrm{TiO} 2$ particles: the influence of inorganic anions," Journal of Photochemistry and Photobiology A: Chemistry, vol. 165, no. 1-3, pp. 201-207, 2004.

[156] H. C. Liang, X. Z. Li, Y. H. Yang, and K. H. Sze, "Effects of dissolved oxygen, pH, and anions on the 2,3-dichlorophenol degradation by photocatalytic reaction with anodic TiO2 nanotube films," Chemosphere, vol. 73, no. 5, pp. 805-812, 2008.

[157] X. Zhu, M. A. Nanny, and E. C. Butler, "Effect of inorganic anions on the titanium dioxidebased photocatalytic oxidation of aqueous ammonia and nitrite," Journal of Photochemistry and Photobiology A: Chemistry, vol. 185, no. 2-3, pp. 289-294, 2007.

[158] C. Guillard, E. Puzenat, H. Lachheb, A. Houas, and J.-M. Herrmann, "Why inorganic salts decrease the TiO 2 photocatalytic efficiency," International Journal of Photoenergy, vol. 07, no. 1i, pp. 1-9, 2005.

[159] M. Bekbölet and I. Balcioglu, "Photocatalytic degradation kinetics of humic acid in aqueous $\mathrm{TiO} 2$ dispersions: The influence of hydrogen peroxide and bicarbonate ion," Water Science and Technology, vol. 34, pp. 73-80, 1996.

[160] M. N. Sugihara, D. Moeller, T. Paul, and T. J. Strathmann, "TiO2-photocatalyzed transformation of the recalcitrant X-ray contrast agent diatrizoate," Applied Catalysis B: Environmental, vol. 129, pp. 114-122, 2013.

[161] Z. Hua, M. P. Zhang, Z. F. Xia, and G. K. C. Low, "Titanium dioxide mediated photocatalytic degradation of monocrotophos," Water Research, vol. 29, pp. 2681-2688, 1995.

[162] C. S. Uyguner and M. Bekbolet, "Contribution of Metal Species to the Heterogeneous Photocatalytic Degradation of Natural Organic Matter," International Journal of Photoenergy, vol. 2007, pp. 1-8, 2007.

[163] M. J. López-Muñoz, J. Aguado, and B. Ruperez, "The influence of dissolved transition metals on the photocatalytic degradation of phenol with TiO2," Research on Chemical ..., vol. 33, no. 3, pp. 377-392, 2007.

[164] M. Keshmiri, M. Mohseni, and T. Troczynski, "Development of novel TiO2 sol-gel-derived composite and its photocatalytic activities for trichloroethylene oxidation," Applied Catalysis B: Environmental, vol. 53, no. 4, pp. 209-219, 2004.

[165] J. Yu, J. Xiong, B. Cheng, and S. Liu, "Fabrication and characterization of Ag-TiO2 multiphase nanocomposite thin films with enhanced photocatalytic activity," Applied Catalysis B: Environmental, vol. 60, no. 3-4, pp. 211-221, 2005. 
1 Table Captions

2

3 Table 1: Summary of inhibition mechanisms

4 Table 2: Reaction rates of various anions with hydroxide radicals

5 Table 3: Effect of $\mathrm{Cl}^{-}$on the breakdown of various targets

6 Table 4: Effect of phosphate on the breakdown of various targets

7 Table 5: Effect of $\mathrm{SO}_{4}{ }^{2-}$ on the breakdown of various targets

8 Table 6: Effect of carbonate on the breakdown of various targets

9 Table 7: Effect of nitrate on the breakdown of various targets

10 Table 8: Redox potentials of metal ions in solution (adapted from [55])

11 Table 9: Effect of $\operatorname{Cr}($ III) on the breakdown of various targets

12 Table 10: Effect of copper on the breakdown of various targets

13 Table 11: Scavenging rates of various alcohols with hydroxide radicals (Adapted from

14 [152])

15 Table 12: Testing of Adhesion of Catalyst to Support

16 Table 13: Summary of regeneration methods 
1 Table 1: Summary of inhibition mechanisms

\begin{tabular}{|l|l|l|}
\hline Mechanism & Sample inhibitors & Occurs at/in \\
\hline \hline Surface blockage & $\mathrm{H}_{2} \mathrm{PO}_{4}{ }^{-}, \mathrm{Cr}^{3+}$, Humic acid & Surface \\
\hline Scavenging & $\mathrm{I}^{-}, \mathrm{Cl}^{-}, \mathrm{CO}_{3}{ }^{2-}$, Alcohols & Bulk and surface \\
\hline Complexation with target & $\mathrm{DOM}, \mathrm{Cu}^{2+}, \mathrm{Ca}^{2+}$ & Bulk \\
\hline Recombination Promoter & $\mathrm{Cr}, \mathrm{Mn}$ & Surface \\
\hline Light absorption & $\mathrm{DOM}, \mathrm{NO}_{3}{ }^{-}$ & Bulk \\
\hline Bandgap shifting & $\mathrm{MnO}_{2}$ & Surface \\
\hline Particle aggregation & Divalent ions & Surface \\
\hline
\end{tabular}

2 
1 Table 2: Reaction rates of various anions with hydroxide radicals

\begin{tabular}{lll}
\hline Ion & Scavenging rate (M s) & Ref. \\
\hline $\mathrm{CO}_{3}{ }^{2-}$ & $2.8-3.9 \times 10^{8}$ & {$[152,153]$} \\
$\mathrm{HCO}_{3}{ }^{-}$ & $5.7-8.5 \times 10^{6}$ & {$[152,153]$} \\
$\mathrm{Cl}^{-}$ & $1 \times 10^{6}-1 \times 10^{10}$ & {$[28,152]$} \\
$\mathrm{Br}^{-}$ & $10^{8}-10^{10}$ & {$[28]$} \\
$\mathrm{NO}_{3}{ }^{-}$ & $<1.5 \times 10^{5}$ & {$[28]$} \\
$\mathrm{HPO}_{4}{ }^{2-}$ & $5.9 \times 10^{5}-5 \times 10^{6}$ & {$[28,153]$} \\
$\mathrm{H}_{2} \mathrm{PO}_{4}{ }^{-}$ & $<1.2 \times 10^{7}$ & {$[28]$} \\
$\mathrm{PO}_{4}{ }^{3-}$ & $7 \times 10^{6}-1 \times 10^{7}$ & {$[28,153]$} \\
$\mathrm{HSO}_{4}{ }^{2-}$ & $3.5 \times 10^{5}-1.6 \times 10^{6}$ & {$[28,154]$} \\
$\mathrm{HSO}_{3}{ }^{-}$ & $4.5 \times 10^{9}-9.5 \times 10^{9}$ & {$[28,36]$} \\
$\mathrm{I}^{-}$ & $10^{10}$ & {$[152]$} \\
& &
\end{tabular}


1 Table 3: Effect of $\mathrm{Cl}^{-}$on the breakdown of various targets

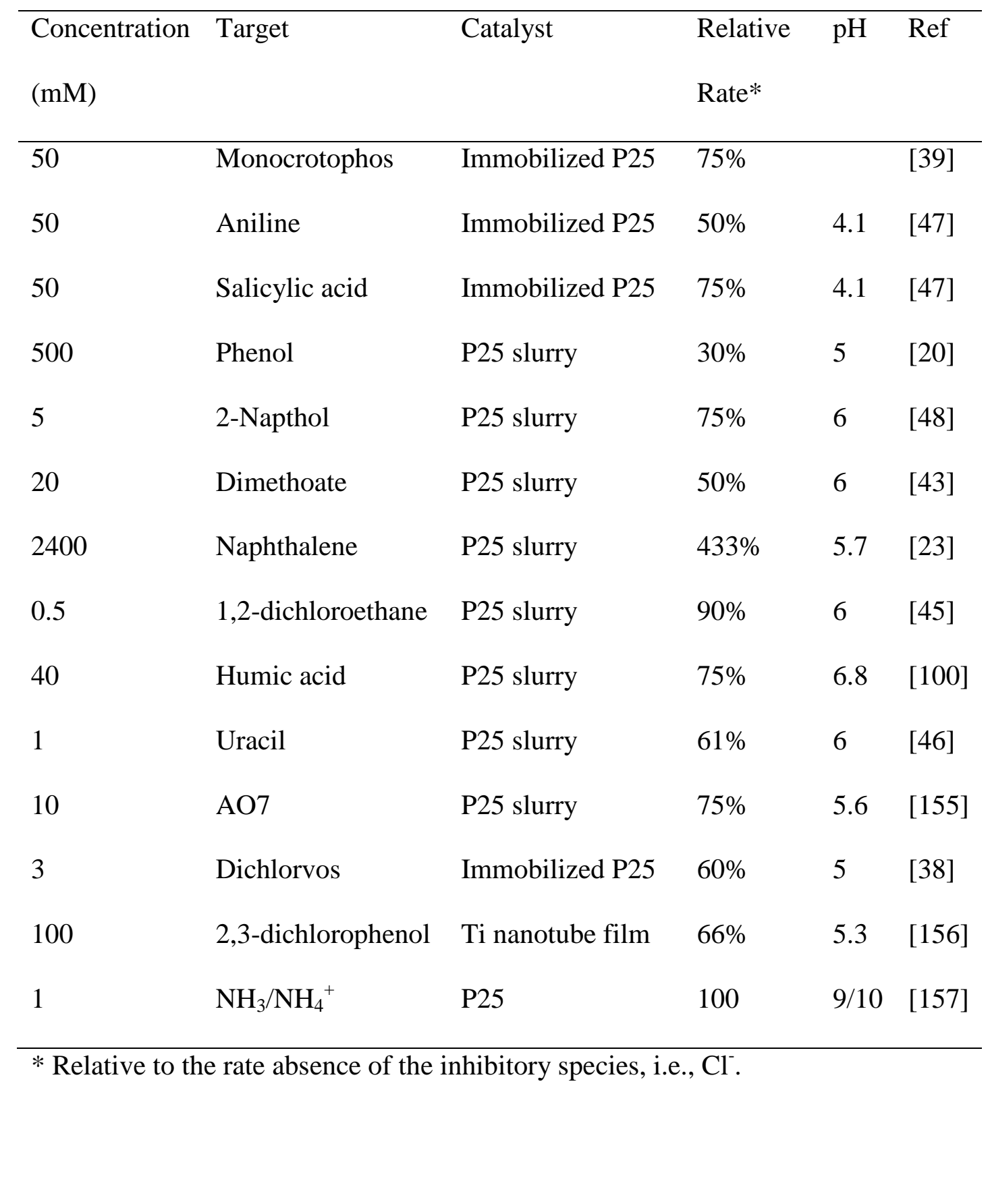


1 Table 4: Effect of phosphate on the breakdown of various targets

\begin{tabular}{|c|c|c|c|c|c|}
\hline Concentratio & & & & & Referen \\
\hline $\mathrm{n}(\mathrm{mM})$ & Target & Catalyst & Relative Rate & pH & ce \\
\hline 0.5 & 1,2-dichloroethane & P25 Slurry & $64 \%$ & 6 & {$[45]$} \\
\hline 1 & Ethanol & Immoblized P25 & $56 \%$ & 4.1 & [47] \\
\hline 1 & Aniline & Immoblized P25 & $52 \%$ & 4.1 & [47] \\
\hline 1 & Salicylic acid & Immoblized P25 & $35 \%$ & 4.1 & [47] \\
\hline 10 & MX-5B & P25 slurry & $183 \%$ & 2.4 & [37] \\
\hline 2 & Formic Acid & P25 slurry & $38 \%$ & 3.5 & [35] \\
\hline 2 & Benzene & P25 slurry & $150 \%$ & 3.5 & [35] \\
\hline 100 & CBX & P25 slurry & $250 \%$ & 2.4 & [37] \\
\hline & & Immobilized Pt- & & & \\
\hline 2 & TCE & anatase & $69 \%$ & 9 & [17] \\
\hline 4 & Humic acid & P25 slurry & $12 \%$ & 6.8 & {$[50]$} \\
\hline 10 & Methylene blue & P25 slurry & $80 \%$ & & [94] \\
\hline 1 & AO7 & P25 slurry & $75 \%$ & 5.6 & {$[155]$} \\
\hline 1 & $\mathrm{NH}_{3} / \mathrm{NH}_{4}^{+}$ & P25 & $200 \%$ & 9 & [157] \\
\hline
\end{tabular}

2 
1 Table 5: Effect of $\mathrm{SO}_{4}{ }^{2-}$ on the breakdown of various targets

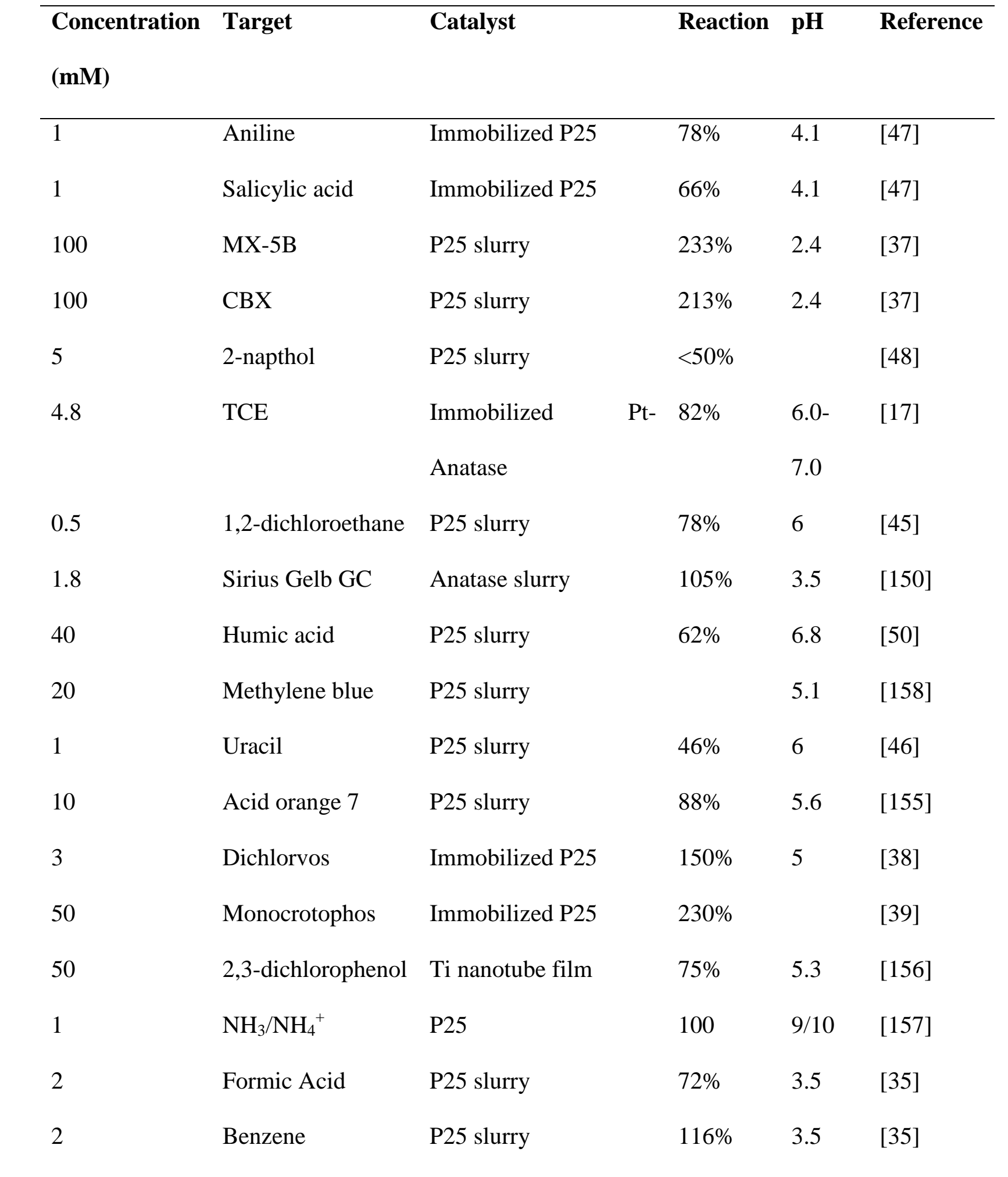

2 
1 Table 6: Effect of carbonate on the breakdown of various targets

\begin{tabular}{|c|c|c|c|c|c|}
\hline $\begin{array}{l}\text { Concentration } \\
(\mathrm{mM})\end{array}$ & Target & Catalyst & Relative & pH & Ref \\
\hline 110 & Aniline & P25 slurry & $330 \%$ & 10.8 & [42] \\
\hline 0.5 & $\begin{array}{l}\text { 1,2- } \\
\text { dichloroethane }\end{array}$ & P25 slurry & $87 \%$ & $\sim 6$ & [45] \\
\hline 30 & Naphthalene & P25 slurry & $17 \%$ & 11 & {$[23]$} \\
\hline 10 & Naphthalene & P25 slurry & $33 \%$ & 8.5 & {$[23]$} \\
\hline 1.5 & Dimethoate & P25 slurry & $171 \%$ & 6 & {$[43]$} \\
\hline 100 & Humic acid & P25 slurry & $50 \%$ & 6.8 & [159] \\
\hline 1 & Uracil & P25 slurry & $35 \%$ & 8 & {$[46]$} \\
\hline 10 & Methylene Blue & P25 slurry & $117 \%$ & NR & {$[94]$} \\
\hline 10 & D\&C Green 8 & P25 slurry & $25 \%$ & NR & [94] \\
\hline 10 & Diatrizoate & P25 slurry & $43 \%$ & 8 & {$[160]$} \\
\hline 10 & Acid Orange 7 & P25 slurry & 100 & 5.6 & {$[155]$} \\
\hline 1 & $\mathrm{NH}_{3} / \mathrm{NH}_{4}^{+}$ & $\mathrm{P} 25$ & 100 & 9 & [157] \\
\hline 1 & $\mathrm{NH}_{3} / \mathrm{NH}_{4}^{+}$ & $\mathrm{P} 25$ & $25 \%$ & 11 & {$[157]$} \\
\hline
\end{tabular}


1 Table 7: Effect of nitrate on the breakdown of various targets

\begin{tabular}{|c|c|c|c|c|}
\hline Concentration & \multirow[b]{2}{*}{ Target } & \multirow[b]{2}{*}{ Catalyst } & \multicolumn{2}{|c|}{ Relative } \\
\hline$(\mathrm{mM})$ & & & Rate & Ref \\
\hline 10 & Dimethoate & P25 slurry & $162 \%$ & [43] \\
\hline \multirow{3}{*}{0.5} & $1,2-$ & \multirow{3}{*}{ P25 slurry } & \multirow{3}{*}{$93 \%$} & \multirow{3}{*}[45]{} \\
\hline & & & & \\
\hline & Dichloroethane & & & \\
\hline 100 & 2-napthol & P25 slurry & $94 \%$ & {$[48]$} \\
\hline 40 & Humic Acid & P25 slurry & $191 \%$ & {$[50]$} \\
\hline 20 & Methylene Blue & P25 slurry & $100 \%$ & [158] \\
\hline 1 & Uracil & P25 slurry & $84 \%$ & {$[46]$} \\
\hline $10\left(\right.$ as $\mathrm{NaNO}_{3}$ ) & Methylene Blue & P25 slurry & $98 \%$ & {$[94]$} \\
\hline $10\left(\right.$ as $\left.\mathrm{HNO}_{3}\right)$ & Methylene Blue & P25 slurry & $156 \%$ & {$[94]$} \\
\hline 10 & D\&C Green 8 & P25 slurry & $21 \%$ & {$[94]$} \\
\hline 10 & FD\&C Red 2 & P25 slurry & $81 \%$ & {$[94]$} \\
\hline 10 & Acid Orange 7 & P25 slurry & 90 & [155] \\
\hline \multirow{2}{*}{100} & Ethanol, Aniline, & \multirow{2}{*}{ Immobilized P25 } & \multirow{2}{*}{$100 \%$} & \multirow{2}{*}[47]{} \\
\hline & Salicylic Acid & & & \\
\hline 50 & Monocrotophos & Immobilized P25 & 80 & [161] \\
\hline 50 & $2,3-$ & Ti nanotube film & $85 \%$ & [156] \\
\hline & dichlorophenol & & & \\
\hline
\end{tabular}


1 Table 8: Redox potentials of metal ions in solution (adapted from [55])

\begin{tabular}{ll}
\hline Redox Pair & Potential (V vs. NHE) \\
\hline $\mathrm{Ca}^{2+} / \mathrm{Ca}$ & -2.868 \\
$\mathrm{Na}^{+} / \mathrm{Na}$ & -2.71 \\
$\mathrm{Mn}^{2+} / \mathrm{Mn}$ & -1.185 \\
$\mathrm{Mn}^{3+} / \mathrm{Mn}^{2+}$ & 1.5415 \\
$\mathrm{Cr}^{3+} / \mathrm{Cr}$ & -0.744 \\
$\mathrm{Co}^{2+} / \mathrm{Co}$ & -0.28 \\
$\mathrm{Ni}^{2+} / \mathrm{Ni}$ & -0.257 \\
$\mathrm{~Pb}^{2+} / \mathrm{PB}$ & -0.1262 \\
$\mathrm{Cu}^{2+} / \mathrm{Cu}$ & 0.3419 \\
$\mathrm{Cu}^{2+} / \mathrm{Cu}$ & 0.153 \\
$\mathrm{Hg}^{2+} / \mathrm{Hg}$ & 0.7973 \\
$\mathrm{Zn}^{2+} / \mathrm{Zn}$ & -0.7618 \\
\hline
\end{tabular}

2 
1 Table 9: Effect of $\mathrm{Cr}$ (III) on the breakdown of various targets

\begin{tabular}{llllll}
\hline Concentration ( $\mathbf{\mu M})$ & Target & Catalyst & Relative Rate & pH & Reference \\
\hline 200 & Dimethoate & P25 slurry & $3 \%$ & 6 & {$[43]$} \\
50 & 2-napthol & P25 slurry & $<10 \%$ & - & {$[48]$} \\
280 & Phenol & P25 slurry & $16 \%$ & 6.75 & {$[52]$} \\
0.969 & Humic acid & P25 slurry & $74 \%$ & 6.7 & {$[162]$}
\end{tabular}

2

3 
1 Table 10: Effect of copper on the breakdown of various targets

\begin{tabular}{|l|l|l|l|l|l|l|}
\hline Target & Catalyst & Relative & $\mathbf{p H}$ & Peak & Inhibition & Ref. \\
& & rate & & promotion & start $(\boldsymbol{\mu M})$ & \\
$\mathbf{( \mu M )}$ & & & \\
\hline Methanol & P25 slurry & $166 \%$ & 8.5 & 2 & 15 & {$[51]$} \\
\hline Phenol & P25 slurry & $175 \%$ & 3.5 & 1000 & 7500 & {$[163]$} \\
\hline Toluene & P25 slurry & $200 \%$ & 3.5 & 1 & 30 & {$[63]$} \\
\hline 2-napthol & P25 slurry & $150 \%$ & N.R. & 50 & 200 & {$[48]$} \\
\hline Glyphosate & P25 slurry & 250 & 6 & 10 & - & {$[87]$} \\
\hline
\end{tabular}

2 
1 Table 11: Scavenging rates of various alcohols with hydroxide radicals (Adapted from

2 [152])

\begin{tabular}{ll}
\hline Alcohol & Scavenging rate $\left(\mathbf{M ~ s}^{-1}\right)$ \\
\hline Methanol & $10^{9}$ \\
Ethanol & $1.9 \times 10^{9}$ \\
Isopropanol & $1.9 \times 10^{9}$ \\
1-Butanol & $1.7 \times 10^{8}$ \\
\hline
\end{tabular}

3

4 
1 Table 12: Testing of Adhesion of Catalyst to Support

\begin{tabular}{|c|c|c|c|c|}
\hline Catalyst & Support & Method & Result & Ref. \\
\hline CVD & "Glass & Release & $\begin{array}{l}\text { Release was seen, amount } \\
\text { dependant on conditions. See Text }\end{array}$ & [131] \\
\hline SG/P25 & Glass & Scratch test & 10N Require to cause scratch & [164] \\
\hline P25 & Al Foam & Release & No release & {$[113]$} \\
\hline P25 & Steel & Release & No release & {$[128]$} \\
\hline SG & $\begin{array}{l}\text { Glass and } \\
\text { quartz }\end{array}$ & Release & No release & {$[128]$} \\
\hline SG & Steel & $\begin{array}{l}\text { Tape test (ASTM } \\
\text { D3359B-02) }\end{array}$ & No release & {$[110]$} \\
\hline SG & Si & Tape test & No release & {$[112]$} \\
\hline SG & $\begin{array}{l}\text { Soda Lime } \\
\text { Glass }\end{array}$ & Scratch test & $\begin{array}{l}\text { Slight damage with fingernail } \\
\text { with large pressure }\end{array}$ & {$[112]$} \\
\hline SG & $\begin{array}{l}\text { Borosilicate } \\
\text { Glass }\end{array}$ & Abrasion & $\begin{array}{l}\text { No damage with paper with or } \\
\text { without solvents }\end{array}$ & {$[112]$} \\
\hline $\begin{array}{l}\text { Ag } \\
\text { doped } \\
\text { LPD }\end{array}$ & Quartz & $\begin{array}{l}\text { Scratch/tape test/ } \\
\text { sonication }\end{array}$ & No release & [165] \\
\hline SG & Steel & Pencil scratch test & Scratched by 4B & [111] \\
\hline SG/P25 & Steel & Pencil scratch test & Not damaged by $6 \mathrm{H}$ & {$[111]$} \\
\hline SG & Steel & Tape test & No release & [111] \\
\hline SG/P25 & Steel & Tape test & No release & {$[111]$} \\
\hline P25 & Quartz & Release & Delamination occurred if $\mathrm{pH}<3$ or & [124] \\
\hline
\end{tabular}




\begin{tabular}{|l|l|l|l|l|}
\hline & optical fibres & & $>11$ or at high ionic strength & \\
\hline SG/P25 & Steel & Tape Test (ASTM & None for <50 g/l, at 50 slight & [116] \\
& & D3359B-02) & release (4B) 0B by 100 g/l & \\
\hline Plasma & Glass beads & Release & No delamination but significant & {$[129]$} \\
\hline P25 & Steel mesh & Release & erosion & \\
\hline P25 & Glass beads & Release & No Release & {$[127]$} \\
\hline SG & Glass beads & Release & 33\% of coating mass released & [126] \\
\hline
\end{tabular}

1

2 
1 Table 13: Summary of regeneration methods

\begin{tabular}{ll}
\hline Method & Mechanism \\
\hline Illumination & Photoinduced degradation of foulant \\
Solvent rinse & Desorption of foulant \\
Acid/base rinse & Change in solubility of foulant or \\
& surface charge of catalyst \\
Thermal treatment & Desorption or pyrolysis of foulant \\
Other chemical treatment & Breakdown of target \\
\hline
\end{tabular}

2

3

4

5

6

7

8

9

10

11

12

13

14 


\section{Figure Caption}

2

3 Figure 1: Redox potentials of various metal ions [55] and $\mathrm{TiO}_{2}$ as a function of $\mathrm{pH}$ after 4 data in (6). 


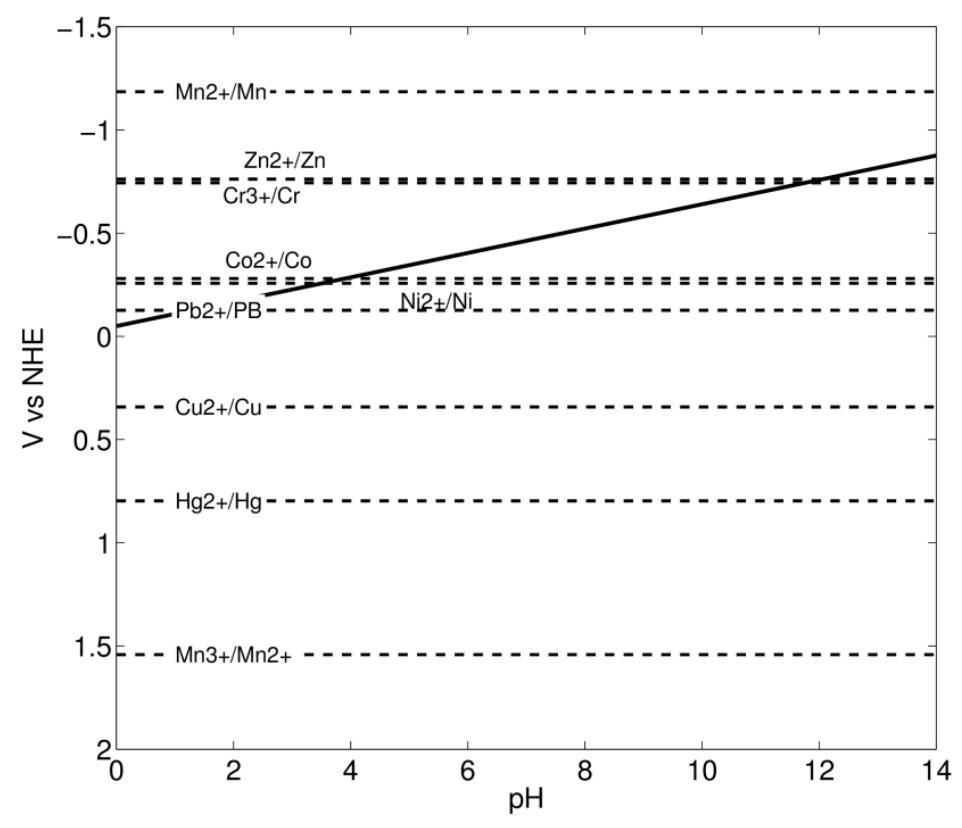

3 Figure 1: Redox potentials of various metal ions [55] and $\mathrm{TiO}_{2}$ as a function of $\mathrm{pH}$ after 4 data in (6). 